5 Research Square
Preprints are preliminary reports that have not undergone peer review.

They should not be considered conclusive, used to inform clinical practice, or referenced by the media as validated information.

\title{
Niche Differentiation and Co-Occurrence Network of Fungal Communities Associated with Host Affiliations in an Extremely Arid Desert Ecosystem
}

\section{Yiling Zuo}

Hebei University College of Life Sciences https://orcid.org/0000-0001-6919-2408

Xia Li

Hebei University College of Life Sciences

Jingya Yang

Hebei University College of Life Sciences

Jiaqiang Liu

Hebei University College of Life Sciences

Xueli He ( $\nabla$ xlh3615@126.com )

Hebei University College of Life Sciences https://orcid.org/0000-0002-2783-3390

Lili Zhao

Hebei University College of Life Sciences

\section{Research}

Keywords: Endophytic fungi, Illumina MiSeq sequencing, Host affiliations, Microbiome niche differentiation, Co-occurrences network, Extremely arid desert ecosystem

Posted Date: December 17th, 2020

DOI: https://doi.org/10.21203/rs.3.rs-129101/v1

License: (c) (i) This work is licensed under a Creative Commons Attribution 4.0 International License.

Read Full License 


\section{Abstract}

Background: Desert shrubs represent high productivity and play essential roles in maintaining the biodiversity and stability of ecosystem functioning in arid desert ecosystems. These xerophytic plants provide specific biotic and abiotic conditions for the resident specialist microorganisms. However, a robust understanding of the structural composition of the fungal microbiome associated with desert plants and especially the relationship between above- and belowground communities is currently lacking. In this study, we examined the endophytic fungal communities associated with the root, stem, and leaf tissues of five desert shrubs using Illumina MiSeq sequencing of internal transcribed spacer 2 (ITS2) sequences.

Results: A total of 337 operational taxonomic units (OTUs) of endophytic fungi were identified at a $97 \%$ sequence similarity level. Pleosporales were dominant and played an irreplaceable role as keystone species in maintaining the connectivity and complexity of the fungal networks. Desert shrub identity significantly affected the community composition of the endophytic fungi in different tissues. Compared with the fungi in the aboveground tissues, root-associated fungi represented the most abundant reservoir of biodiversity in the desert habitat and displayed significantly high tissue specificity. Interestingly, the aboveground stems and leaves showed higher taxonomic overlap with underground root tissues than with each other. The root fungal network revealed the highest connectivity, and the interspecies relationships between desert fungal OTUs revealed a high percentage of co-presence rather than mutual exclusion. In addition, members of Hypocreales played a central role in connecting the above- and belowground fungal networks.

Conclusions: This study represents the first example of research revealing plant-fungus endophytic associations in an extremely arid desert ecosystem with the simultaneous consideration and comparison of above- and belowground niches. Understanding the complex host-microbe interactions associated with desert plants could provide a basis for the exploitation of plant-fungus associations in the manipulation of the shrub microbiome for ecological restoration purposes.

\section{Background}

Interorganism associations between plants and microbial communities represent symbiotic relationships, with these taxa having coevolved for centuries [1]. The microbial communities can be referred to as the host's second or extended genome and are therefore critical for the health of their multicellular hosts [2, 3]. Fungal endophytes, as an important component of microbial diversity, play essential roles in regulating multiple ecosystem functions and enhancing ecosystem stability [4-6]. These assemblages present extensive host and ecological ranges and are even distributed in habitats that are stressful to plants, such as desert regions [7-9]. The establishment of particular fungus-plant mutualistic relationships can confer thermotolerance, drought resistance, and a multitude of functional capabilities that enhance the survival, primary productivity and community structure of plants [10-12]. Arid desert is a unique habitat type with extreme conditions (e.g., low water availability, high salinity, high irradiance, 
and low nutrient availability) that pose challenges for the present biota, and the reservoir of fungal biodiversity adapted to extreme arid desert conditions is incompletely described. Thus, more insights into the endophytic fungal diversity and distribution patterns in desert environments are needed to fully elucidate plant-fungus interactions.

Fungal microorganisms tend to establish strong links with their hosts and show high host specificity; the interruption of these associations may result in the loss of host adaptability [13-15]. As a consequence of the reliance of endophytic fungi on the plant's inner environment for growth, plant species identity therefore presumably plays a particularly decisive role in fungal colonization of internal tissues $[16,17]$. Several studies have documented the significant effects and selective pressure of host plants on endophytic fungal species and community composition [18-22]. For example, Yao et al. [19] found that plant identity had a greater effect on endophytic fungal community composition than epiphytic fungi in the leaves of six mangrove species in South China, and Martínez-García et al. [20] showed differences in the arbuscular mycorrhizal fungal communities under different shrubs in a semiarid environment. Plantfungus interactions have developed as a response to drought in desert ecosystems [21, 22]. In arid desert areas, different shrub species generate islands of fertility and grow on resource-rich patches, which leads to the heterogeneous distribution of substrate resources and reveals the potential of the host genotype to induce the establishment of specific microbial communities $[15,20,23]$. Considering the spatial differences in fungal communities and varied specificity among host species, it is therefore essential to investigate fungal community composition to select representative plant species in desert ecosystems that are distributed in the same area and that are exposed to the same fungal pool [24-26].

The above- and belowground tissues of plants potentially represent distinct microbial habitats, such as the soil rhizosphere and the root, stem and leaf endospheres, which may host contrasting fungal communities by providing specific biotic and abiotic conditions for the resident microorganisms $[3,27$, 28]. Disentangling the niche differentiation of fungal communities in different plant tissues is very useful for describing patterns of plant-microbe interactions [29]. Recently, most attention has been dedicated to niche differentiation of microbes at the rhizospheric soil-root interface [20,30], in the leaf and root endospheres [31-33], and even in different organs of plants [15, 27]. For example, Martínez-García et al. [20] demonstrated that rhizospheric soil arbuscular mycorrhizal fungal communities showed great differences from the fungal communities in root habitats in desert shrubs. In addition, Guevara-Araya et al. [33] observed significant differences in the community composition of endophytic fungi between leaf and root tissues of Aristolochia chilensis in an arid ecosystem, and Durand et al. [15] revealed contrasting aboveground (leaf and stem) and belowground (soil and root) fungal communities collected from poplar at a Hg phytomanagement site using ITS ribosomal RNA (rRNA) gene pyrosequencing. Despite the evidence of the specialization of microbiota to their respective niches, the taxonomic overlap of these microbes within different tissues has been less documented. Bai et al. [34] established Arabidopsis leafand root-derived microbiota culture collections and found large overlap in the genome-encoded functional capabilities of leaf- and root-derived bacteria, which suggests the possibility of reciprocal relocation between root and leaf microbiota members. Nevertheless, research involving the overlap of fungal communities in different plant tissue niches is quite limited [35], especially in extremely arid desert 
ecosystems. Understanding niche differentiation and fungal interactions above and below ground is essential to explain how these symbioses confer benefits and ecological adaptations to plants in desert areas [36].

Multispecies assemblages usually do not live in isolation but instead form interactive relationships through mutualistic or competitive connections [37]. These interactive connections ultimately result in the construction of complex interspecies networks that maintain the structure of an ecological community and consequently the functions of the ecosystem $[38,39]$. Describing the architecture of these networks may help to decipher underlying species coexistence and ecosystem stability [40]. Co-occurrence network analysis has proven to be a useful tool for analysing microbial relationships and has recently been used to study complex ecological systems, such as bacterial or fungal communities in various environments [41-43]. The characteristics of keystone species, member interactions and community organization can be predicted by network analysis to determine the importance of operational taxonomic units (OTUs) and their associations in the community $[44,45]$. Recently, the taxon co-occurrence patterns of fungal networks have received increased levels of attention. Durand et al. [15] compared the fungal network structures in different tissue habitats of poplar and indicated that $80 \%$ of the soil fungal species were negatively correlated revealing the dominance of a pattern of mutual exclusion. However, there remains a lack of studies assessing the links across different niche habitats, which could provide new insights into the way fungal interactions are organized in above- and belowground environments.

The Anxi Extreme Arid Desert of the National Nature Reserve in Gansu Province, Northwest China, is located at the intersection of an Asian temperate desert, an extremely arid desert and a typical desert region, and has sparse native vegetation composed of shrubs [46]. Ephedra przewalskii, Reaumuria soongorica, Sympegma regelii, Nitraria sphaerocarpa and Salsola passerina are typical endemic species of extreme arid deserts in Northwest China. These xerophytic species, characterized by exceptionally high drought resistance, are challenged by several forms of abiotic stress and highly adapted to their environment. The long-term evolution of desert ecosystems has resulted in the development of special characteristics and unique associations of endophytes with these host plants. It is speculated that beneficial endophytes confer the ability of the host to tolerate drought and allow these plants to become pioneers in extremely arid environments $[47,48]$. To the best of our knowledge, no reports on the distribution patterns of the endophytic fungi associated with these prevalent plant species in extreme arid deserts are available.

Our previous investigations predominately focused on the spatial patterns of desert plant root-associated fungi, such as arbuscular mycorrhizal fungi and dark septate endophytes [49-53], and demonstrated the geographic and host affiliations of fungi that are symbiotic with ecologically important plants in arid desert. However, there are still important gaps in our understanding of the occurrence and distribution pattern of fungal endophytes in different tissues of desert plants. In the present study, the genetic diversity of the endophytic fungal microbiota and its relationships with the plant communities in an extremely arid desert in Northwest China were determined using Illumina MiSeq sequencing techniques. We hypothesize that plant species influence the structure of the endophytic fungal communities in desert 
areas. We also characterized the endophytic fungal community composition in different tissue niches, such as in the leaf, stem and root tissues, and analysed the niche differentiation and taxonomic overlap in the above- and belowground environments. Co-occurrence network analysis was also used to investigate the composition and assembly of the fungal communities in these samples. We addressed the following questions: 1) How variable are the fungal communities associated with different shrubs within the same area in the extremely arid desert? 2) Do the endosphere fungal communities vary among the different plant tissue niches? 3) How do the aboveground fungal communities relate to the belowground fungal communities?

\section{Results}

Characterization of Illumina sequencing data

After removing sequences of low quality, potential chimeras and singletons, the remaining non-chimeric fungal internal transcribed spacer 2 (ITS2) sequences $(2,783,159$ in total) were clustered into 504 operational taxonomic units (OTUs) at a 97\% sequence similarity level. Of these 504 OTUs, 421 $(2,692,818$ reads) were identified as fungal OTUs. We then excluded the OTUs with $<10$ reads from all the samples, and the number of sequences per sample was normalized to the smallest sample size $(39,948$ reads), ultimately resulting in a normalized dataset composed of 337 fungal OTUs (1,677,816 reads). The identified fungal OTUs included 280 Ascomycota, 54 Basidiomycota, and 3 Rozellomycota, representing 3 phyla, 20 classes, 49 orders, 102 families, 163 genera and 219 species. A total of 124 relatively abundant OTUs (> 1000 reads) accounted for $99.9 \%$ of the reads for endophytic fungi (Additional file 1: Table S1). The DNA sequences of Dothideomycetes (29.84-81.92\%) were the most abundant at the class level, and those of Pleosporales (29.83-74.76\%) were the most abundant at the order level, with varying relative abundances among all samples (Fig. 1a, b). The members of Sordariomycetes (18.27-46.34\%) were mainly distributed in root tissue niches, while members of Tremellomycetes (2.21-30.59\%) were mainly distributed in leaf and stem niches (Fig. 1a). Rarefaction curves for the Sobs index at the OTU level across all samples approached an asymptote and showed that the overall fungal diversity was well represented (Additional file 2: Figure S1).

OTU richness and alpha diversity

Sobs index values were calculated to describe the observed OTU richness. Alpha diversity, including the Shannon diversity index and evenness, was analysed based on OTU richness (Fig. 2). The OTU richness of endophytic fungi in the stems, leaves and roots ranged between 19.0-52.3, 20.3-30.7 and 24.7-104.7 (mean values), respectively, and the root endophytic fungal communities were much more diverse than the aboveground communities (Fig. 2a). The Kruskal-Wallis test revealed that plant species had a significant effect on the OTU richness of the stem endophytic fungi $\left(\chi^{2}=10.939, P=0.027\right)$ but not on that of the leaves $\left(\chi^{2}=3.308, P=0.347\right)$ or roots $\left(\chi^{2}=5.957, P=0.114\right)$. For example, the OTU richness of the stem endophytes in N. sphaerocarpa was significantly higher than that in E. przewalskii, $R$. soongorica and $S$. regelii. In addition, the integrated OTU richness was highly dependent on plant 
compartment effects $\left(\chi^{2}=6.612, P=0.037\right)$. The OTU richness of the stem niche in $N$. sphaerocarpa was comparable with that of the leaf samples from $S$. regelii, N. sphaerocarpa and S. passerina and root samples from S. regelii and $N$. sphaerocarpa (Fig. 2a). In terms of the Shannon diversity and evenness estimates, we also found significant variation in the stem tissues among the 5 plant species $(P<0.05)$ (Fig. 2b, c).

Community composition of endophytic fungi

The composition and overlap of endophytic fungi among the plant species and tissue niches were documented (Additional file 2: Figure S2). Among the identified fungi, $R$. soongorica represented the highest percentages of unique OTUs in the leaf $(29.08 \%)$ and root $(36.30 \%)$ tissues, and only 7 OTUs ( 1.16 and $3.57 \%$ ) were shared by the 5 plant species (Additional file 2: Figure S2b, c). In addition, $N$. sphaerocarpa and S. passerina exhibited the highest proportion of unique OTUs (26.97 and $28.29 \%$ ) in the stem samples, with 16 shared OTUs (5.26\%) occurring among plant species (Additional file 2: Figure S2a). Furthermore, 81 OTUs (12.05\%) were shared by the leaf, stem and root tissue niches, with the root niche exhibiting the highest percentage of unique OTUs (41.54\%) of endophytic fungi (Additional file 2: Figure S2d). Notably, the OTUs of leaves (10.36\%) and stems $(10.48 \%)$ shared greater proportion of taxa with roots than with each other $(2.46 \%)$.

A heatmap was constructed based on the top 50 most abundant OTUs to reveal the varied occurrence of relatively abundant fungal OTUs among the different plant species and niche habitats (Fig. 3). Among the endophytic fungi distributed in stem tissues (Fig. 3a), four OTUs (Ascomycota OTU480 and OTU212, Sirobasidiaceae 0TU173 and Hazslinszkyomyces lycii OTU398) were distributed dominantly in $N$. sphaerocarpa, and four OTUs (Fusarium proliferatum OTU400, Amphobotrys ricini OTU123, Ascomycota OTU144 and Pleosporales OTU120) were present mainly in S. regelii, while Sporidiobolus pararoseus OTU2 was exclusively found in E. przewalskii. The distribution of leaf fungal OTUs was significantly biased and showed preferences for particular plant species (Fig. 3b). For example, the fungal OTUs (Thyrostroma 0TU11, Acremonium chrysogenum 0TU167, Sporormia grandispora OTU166 and Dothiora OTU9) occurred in only $R$. soongorica; six OTUs (Fusarium 0TU132, Periconia byssoides OTU133, Sporormiella septenaria 0TU142, Cystobasidiomycetes 0TU104, Ascomycota OTU144 and Dematiopleospora 0TU476) were mainly found in S. regelii; Dothideales OTU21 and Ascomycota OTU473 occurred in N. sphaerocarpa; and three OTUs (Apiotrichum montevideense OTU128, Udeniomyces kanasensis OTU390, Neocamarosporium OTU393) were present only in S. passerina. The detectable OTUs in roots with high relative abundance were generally shared by multiple hosts, except Sordariales OTU436 and Preussia polymorpha OTU442, which were restricted to the root samples of $R$. soongorica, and Pleosporales OTU 273, which was exclusively observed in the root of $N$. sphaerocarpa (Fig. 3c). More fungal OTUs with lower abundances were strongly associated with roots of different plant species (Fig. 3c). Furthermore, the relative abundances of some abundant OTUs in different tissue niches significantly differed among plant species $(P<0.05)$, with the most fungal richness differences occurring in the stem niche (Additional file 2: Figure S3a, b, c). The heatmap also displayed the biased occurrence of relatively abundant endophytic OTUs in above- (stem and leaf) and belowground (root) tissues 
(Fig. 3d), which corresponds with the observed significant difference between the clustered above tissue OTUs (stem and leaf) and the root OTUs. Plant tissue niche also exhibited significant effects on relatively abundant OTUs; for example, Thyrostroma OTU10, Aporospora OTU497 and OTU445, and Sordariales OTU278 significantly differed among plant tissues $(P<0.001)$ (Additional file 2: Figure S3d).

Nonmetric multidimensional scaling (NMDS) ordination was used to visualize the differences in endophytic fungal communities among plant species and tissue niches (Fig. 4), and significant dissimilarity among all factors was confirmed with the ANOSIM test. The endophytic fungal community composition of the different niches significantly differed among the five plant species (stem: $\mathrm{F}=0.7911$, $P=0.001$; leaf: $\mathrm{F}=0.4090, P=0.005$; root: $\mathrm{F}=0.2756, P=0.024$ ) and presented characteristics of permutation dispersion with higher heterogeneity of the OTU distribution in different hosts (Fig. 4a, b, C). Moreover, the Bray-Curtis method revealed a significant effect of the plant compartment $(\mathrm{F}=0.2556 ; P=$ 0.001), and the stem and leaf niches were clearly distinguished from the root tissues but did not cluster completely according to their respective niches (Fig. 4d).

Linear discriminant analysis of effect size

We used linear discriminant analysis (LDA) of effect size (LEfSe) to identify the taxa that most likely explain the differences among plant species and tissue niches. Indicator fungal species in the communities with LDA scores of 4 or greater were identified as the best biomarker for each category (Fig. 5). The significant host effect observed for the stem fungal communities was explained by 27 indicator fungal species: 5 for E. przewalskii, 12 for $N$. sphaerocarpa, 6 for $R$. soongorica, 1 for $S$. passerina, and 3 for $S$. regelii (Fig. 5a). In contrast, 8 and 10 indicator taxa were significantly enriched in the leaf and root fungal communities associated with the different plant species, namely, unclassified Ascomycota and Pleosporaceae in the leaves of N. sphaerocarpa; Filobasidiales in the leaves of $S$. passerina; Cystobasidiomycetes, Bulleribasidiaceae and Tremellales in the roots of E. przewalskii; Agaricomycetes in the roots of N. sphaerocarpa; Trichomeriaceae and Comoclathris in the roots of $R$. soongorica; and Pyronemataceae, Lasiobolidium, unclassified Ascobolaceae, and Trichophaeopsis in the roots of $S$. regelii (Fig. 5b, c). Among the plant tissue niches, root samples presented the most abundant species with significant differences (Fig. $5 \mathrm{~d}$ ), evidencing that the strong dominance of root fungal microbiota (38 indicator taxa) explains the niche differentiation of fungal communities in desert regions.

Host and tissue preferences of endophytic fungi

Host-tissue/fungus preference analysis showed that four plant species (S. regelii, N. sphaerocarpa, $S$. passerine, and E. przewalskii) had significant preferences for endophytic fungi, but all tissue niches (stem, root and leaf) presented significant preferences for endophytic fungi (Fig. 6). Alternatively, 49 out of 124 relatively abundant endophytic fungal OTUs significantly displayed both host and tissue preferences. In addition, 21 endophytic fungal OTUs were exclusively displayed significant host preferences, such as 0TU139 (Botryosphaeria fabicerciana), OTU473, OTU144 and OTU212 (Ascomycota), OTU446 (Lasiobolidium spirale), OTU9 (Dothiora) and OTU463 (Comoclathris). Whereas 39 endophytic fungal OTUs were exclusively displayed significant tissue niches preferences, such as 
OTU12 (Comoclathris spartii), OTU110 (Acremonium furcatum), OTU477 (Fusarium redolens), 0TU138 and OTU21 (Neocamarosporium), OTU245 (Ascomycota), OTU497 (Aporospora) and OTU278 (Sordariales) (Fig. 6; Additional file 1: Table S1). In our dataset, 26 pairs of plant species and endophytic fungi showed significantly strong preferences (two-dimensional preferences $(2 D P)>2.7$ ), such as the pairs of E. przewalskii with OTU9 and OTU4 (Endoconidioma populi), S. regelii with OTU144 (Ascomycota), S. passerina with OTU461 (Pleosporaceae), and N. sphaerocarpa with OTU212, OTU480 and OTU473 (Ascomycota) (Fig. 6; Additional file 1: Table S1). In contrast, 44 of 372 tissue niche and endophytic fungus pairs were observed to show significantly strong preferences $(2 D P>2.2)$. Among them, 33 pairs revealed strong preferences between the root tissue niche and endophytic fungal OTUs such as 0TU298 (Monosporascus ibericus), OTU175 (Pleosporales), OTU417 (Sarocladium kiliense), OTU477 (Fusarium redolens) and OTU445 (Aporospora) (Fig. 6; Additional file 1: Table S1).

Co-occurrence networks of endophytic fungi

Co-occurrence analysis resulted in biased patterns of fungal clustering for the different niche habitats and provided information on their corresponding network properties in terms of network connectivity, the clustering coefficient and network density (Fig. 7a, b, c; Additional file 3: Table S2). The root habitat showed the highest network connectivity, exemplified by the highest numbers of nodes (120) and edges (1385) (Fig. 7a, b, c; Additional file 3: Table S2). The root network also had significantly higher mean values of network density ( 0.194 versus 0.098 and 0.100$)$ and centralization ( 0.247 versus 0.181 and 0.134 ) than the stem and leaf networks, while the clustering coefficient for the leaf habitat was higher than those for the stem and root networks (Additional file 3: Table S2). Notably, the analysis of the relationships between fungal OTUs in the whole dataset revealed a high percentage of co-presence rather than mutual exclusion (Additional file 3: Table S2). OTUs from Pleosporales were the most abundant in all three networks, accounting for $46.91 \%$ of the total OTUs in stems, $51.90 \%$ of the total OTUs in leaves and $39.17 \%$ of the total OTUs in roots (data not shown). According to the number of connections established with the rest of the network, 10 dominant keystone OTUs were arbitrarily identified here for each habitat based on the number of degrees for each node (Additional file 3: Table S3). We found that the taxa with a high number of degrees but relatively low abundance served as important nodes in terms of maintaining the function and structure of the microbial community (Additional file 3: Table S3). MCODE analysis returned several significant clusters of fungal groups (6 in stems, 6 in leaves and 7 in roots) that were particularly closely connected in the network (Additional file 2: Figure S4), indicating the typical small-world characteristic of the three networks in this arid desert.

To take into account the interactions between the above- and belowground fungal communities, an integrated co-occurrence network was constructed to interpret the relationships among the fungal communities across the different niches (Fig. 7d). The construction of this network led to the identification of 112 nodes and 441 edges, with the highest values of characteristic path length and network heterogeneity (Additional file 3: Table S2). In particular, the full network contained all OTUs exhibiting positive connections and showing a 100\% co-presence percentage (Additional file 3: Table S2). The fungal nodes in the network tended to be shared by all three niche habitats (51.79\%), which 
confirmed the results in terms of the relationships and overlap among the different plant tissues. The nodes shared by leaves-roots and stems-roots accounted for 14.29 and $11.61 \%$ of the total, respectively, while those shared by the leaves and stems accounted for $0.89 \%$ of the total. Additionally, $21.43 \%$ of the nodes appeared to be specific to the root niche habitat. Although the fungal network tended to contain the most OTUs belonging to Pleosporales (47 nodes), eight Hypocreales members were identified as dominant keystone OTUs (Additional file 3: Table S3). MCODE analysis returned eleven significant clusters with network scores ranging between 3 and 18, and the Hypocreales groups produced the rank 1 cluster, which had 20 nodes and 171 edges (Additional file 2: Figure S4).

\section{Discussion}

In the present study, a total of 337 OTUs of endophytic fungi were identified at a $97 \%$ sequence similarity level. This level of endophytic fungal diversity associated with shrubs growing under extreme desert conditions in Northwest China was significantly lower than that associated with plants in subtropical forests, farmland plantations and even wetland ecosystems [19, 37, 41]. Considering the unique habitat provided by arid areas, it seems that the typical harsh environmental conditions of extreme desert lands truly reduce the number of plant endophytes. Rarefaction analyses and richness estimators indicated that much of the total diversity detectable with Illumina-based sequencing was observed. Although a great number of endophytic fungi have been isolated from desert plants worldwide [6, 12, 54-57], this study is the first to describe plant-fungal endophyte associations in an extremely arid desert ecosystem with the simultaneous consideration and comparison of above- and belowground environments.

Thanks to their various life forms and ecological plasticity, fungal assemblages display strong adaptation to extreme environments, and their role is particularly crucial for the recycling of organic matter and favouring nutrient uptake under stressful conditions [58]. Our study showed that Ascomycota were dominant among the desert plants, which is in accordance with the findings of some previous studies $[57,59,60]$. Most Ascomycota members are saprophytic and therefore the main decomposers in habitats, as they can decompose large amounts of refractory organic matter, thus playing an important role in desert nutrient cycling [61]. In this study, the DNA sequences of Dothideomycetes (29.84-81.92\%) were the most abundant at the class level, and those of Pleosporales (29.83-74.76\%)were the most abundant at the order level. Members of Dothideomycetes have been reported to be abundant in endophytic fungal communities in other plant taxa, such as poplars and grapevines (Vitis vinifera) [62, 63]. Pleosporales have been ubiquitously detected in arid and semiarid environments [64], which is consistent with our results. Moreover, we also found that members of Sordariomycetes (18.27-46.34\%) were distributed mainly in root tissues, while Tremellomycetes $(1.21-30.59 \%)$ were distributed mainly in leaves and stems. This differentiation of the fungi in above- and belowground tissues could possibly be the result of resource utilization, which drives the rapid evolutionary radiation of microbes competing for resources, causing them to diverge and adapt to different niches to reduce competition $[18,65]$.

We found that fungal OTU richness was highly dependent on the plant compartment $\left(\chi^{2}=6.612, P=\right.$ 0.037 ) and that the root endophytic fungal communities showed relatively higher OTU richness than 
those in the aboveground tissues. Studies have demonstrated that plant roots can be highly colonized by abundant fungal endophytes and that the deeply and extensively distributed underground root systems of desert plants provide more hosts and substrate for infection by endophytic fungi than aboveground tissues [66]. Although 16 OTUs in the stem tissues were shared by 5 hosts, plant species significantly affected the OTU richness of the stem endophytic fungi $\left(X^{2}=10.939, P=0.027\right)$, which indicates the high variability in endophytic fungi in the stem niche among the 5 plant species. This high variability may be related to the ability of endophytic fungi to penetrate plant tissues and ultimately successfully colonize the endodermis, the pericycle and even the xylem vessels $[3,18,67]$. In particular, it is worth noting that the leaves $(10.36 \%)$ and stems $(10.48 \%)$ showed a greater percentage of shared taxa with those in the root habitat than with each other $(2.46 \%)$ in our study, which indicates the existence of taxonomic overlap in the endophytic fungal assemblages of the root and aboveground compartments. Zarraonaindia et al. [68] investigated the grapevine (Vitis vinifera)-associated microbiota and found that the microbiotas of the leaves, flowers, and grapes shared greater proportions of taxa with the belowground communities (albeit with the soil microbiome) than with each other, suggesting that soil served as a common reservoir for plant microbiotas. Soil harbours an extraordinarily rich diversity of microorganisms and largely determines the initial inoculum of endophytic root-associated microbiota $[34,69,70]$. In arid deserts, the abundant root endophytes may also provide an inoculum source for the colonization of aboveground tissues, thereby leading to taxonomic overlap between aboveground and root tissues.

As expected, plant identity significantly affected the community composition of endophytic fungi, as suggested by our results from the heatmap of fungal relative abundance, the ANOSIM of fungal community structures and the LEfSe analysis. Although host plants in the same arid habitat seem to receive similar fungal propagules [20,34], differences in host chemistry and nutrient contents can affect endophytic fungal colonization and promote differences in the dominant members of the fungal community $[19,71,72]$. Another explanation for the differentiation of the fungal community among plants can be attributed to host/fungus preferences. Our host/fungus preference analysis demonstrated that four plant species (except $R$. soongorica) showed significant preferences for endophytic fungi and that 70 of 124 endophytic fungal OTUs displayed significant host preferences. The five extremely endemic plants in this study belong to different families, and previous studies have demonstrated host preferences of endophytic fungi at the plant family level $[73,74]$. To a certain extent, the enrichment and depletion of specific endophytic microbiomes are not passive processes but rather depend on the active selection of microbial consortia by the plant host $[3,69,75]$. Furthermore, the ability of endophytic fungi to successfully colonize a host plant requires the presence of specific traits, such as the production of cell wall-degrading enzymes, and intricate interplay between the fungi and the host plant's innate immune system $[3,66,67]$. Some endophytic fungi can produce enzymes that dissolve a variety of plant cell walls, allowing them to enter and colonize a wide range of hosts, but a fungal species presenting host specificity may only produce a specific enzyme that permits the endophyte to infect certain host plant cells $[76,77]$. 
Compared with plant species, the structure of the endophytic fungal communities was more obviously differentiated in association with the different tissue niches in our study. The clustering heatmap and the Bray-Curtis method ( $F=0.2556, P=0.001)$ revealed the significant occurrence of endophytic fungal communities in the above- (stem and leaf) and belowground (root) compartments, which is in agreement with previous studies by Tardif et al. [78] and Xiong et al. [18], who demonstrated significant plant compartment effects among plant endophytic microbes. The significant difference between the shoot and root niches observed here may be due to the influence of fundamentally different conditions between the above- and belowground environments in the desert ecosystem $[61,79]$. The light intensity, humidity and temperature of the habitats in which the different microbes survive and the chemical activity of the different tissues against fungal infections can absolutely lead to differentiation in the endophytic fungal communities and niche specificity [80,81]. Although a proportion of fungal OTUs were shared by all the plant tissues, the niche specificity of fungi is highlighted by the existence of specific proportions of OTUs that were exclusively found in the different plant niches. Each of the plant ecological niches provides relevant biotic and abiotic gradients, such as in the availability of soluble organic compounds $[3,19,69]$, and the different ecological processes can also contribute to the high degree of compartment specificity among the fungal endophyte communities [33, 82]. Here, the tissue/fungus preference analysis showed that all tissue niches presented significant preferences for endophytic fungi and that 88 of 124 fungal OTUs revealed significant tissue preferences. In addition, 44 of 372 tissue niche and endophytic fungus pairs were observed to show significantly strong preferences. These results suggest that individual tissue niches as distinct substrates could reflect preferences for dominant taxa [83]; simultaneously, different endophytic fungi also vary in their capacity for utilizing or surviving on a specific substrate [84, 85]. For instance, the deposition of large amounts of carbon in root tissue, such as root exudates, could directly drive the colonization of root-associated fungi $[3,86]$. Furthermore, some leaf endophytic fungi have been shown to harbour corresponding receptors to ensure survival in the phyllosphere environment $[3,87]$.

Co-occurrence analysis revealed that the root niche showed the highest network connectivity and the highest number of interactions (120 nodes and 1385 edges), suggesting that the root endophytic fungal network is more stable and functional than the stem and leaf networks in this arid desert. Studies have indicated that the interspecies relationships in fungal communities could be strengthened by upregulated drought or wetting disturbance [37]. Thus, the strong fungal interactions in the root habitat are likely one of the factors explaining the reasonable adaptation of desert plants to this particular soil type. In our study, MCODE analysis returned several significant clusters of fungal groups ( 6 in stems, 6 in leaves and 7 in roots) in the fungal networks, indicating the typical small-world characteristic of the networks in this arid desert. The links between OTUs in the different modules in the network can also contribute to more intensified interactions among fungal OTUs at a high organizational level of the network [37]. The edges in co-occurrence networks could represent positive or negative correlations and imply a biologically or biochemically meaningful relationship between fungal species $[15,88]$. In our study, the relationships between fungal OTUs in the whole dataset revealed a high percentage of co-presence. Studies have indicated that microbes can establish positive or negative correlations based on their environmental preferences [15]. In arid deserts, fungal assemblages may persist in the community by establishing 
reciprocal symbioses with each other to resist stressful conditions $[15,19,89]$. Additionally, the disconnected microhabitats and the presence of a high number of dormant cells in the bulk sand can also explain the identification of a dominance of co-presence interactions in the arid desert $[11,90]$.

Keystone species are represented by the centralized nodes in the network, have a large influence on 'information' transfer throughout the community, and act to stabilize the microbial community [91, 92]. Interestingly, we found that taxa represented by nodes with a high number of degrees but with relatively low abundance were important in maintaining the function and structure of the microbial community (Table S3). This finding is in agreement with those from a study by Mandakovic et al. [89], who compared microbial co-occurrence networks representing soil bacterial communities along a western slope of the Andes in the Atacama Desert and revealed that highly abundant OTUs were not as important as some of the relatively rare but highly connected species in terms of network dynamics and stability. Xue et al. [93] demonstrated that the removal of keystone taxa from microbial co-occurrence networks significantly decreased the number of edges and average connectivity of the network. Although all of the networks shared similar node OTU names, no overlapping keystone OTUs were found in the networks among the different plant compartments (Table S3). This indicates that role shifts of fungal OTUs occurred in the different plant tissue niches $[37,94]$. However, the keystone species originated from nearly the same taxa at a higher phylogenetic level, for example, members of the order Pleosporales were keystone species in all networks, suggesting that the functional roles of nodes in the networks could be conserved at a higher phylogenetic level [37]. In addition to those of Pleosporales, members of Hypocreales, Chaetothyriales (Cyphellophora) and Eurotiales (Penicillium) played important central roles in connecting the above-and belowground fungal networks, indicating the potential functional features of these species in the studied desert ecosystem. Abundant studies have focused on the entomopathogenic effect of Hypocreales strains and their potential use as biocontrol agents of insects [95-97]; thus, the important connections of this fungus in the co-occurrence network may be related to the biological defence mechanisms of desert plants. Penicillium, a well-known Ascomycota taxon that secretes antibiotics, is also known for its tolerance to low water potential and could develop strong relationships with other members in the module through antibiotics or secondary metabolites [37, 98]. Overall, the occurrence and assembly of the fungal communities in the studied desert habitat were found to be highly correlated with host species and tissue niches, and the identification of the dominant taxa and keystone species could provide essential information for developing strategies to manipulate desert plant-associated microbes for desert vegetation restoration $[18,99]$.

\section{Conclusions}

A total of 337 operational taxonomic units (OTUs) of endophytic fungi were identified in our study. The taxa of Pleosporale were mainly dominated in desert plants and played irreplaceable role as keystone species in maintaining the stability of fungal networks. The occurrence and assembly of fungal communities in desert habitats were highly correlated with host species and tissue niches. Compared with aboveground tissues, root-associated fungi represented the most abundant reservoir of biodiversity in desert habitat, and the aboveground stems and leaves showed higher taxonomic overlap with 
underground root tissues than with each other. There existed strong and positive inter-species connections in desert fungal community, and the root fungal co-occurrence network harbored the highest connectivity and established higher number of interspecies interactions. Our study firstly reported the endophytic fungi communities of desert plants in an extremely arid desert with the simultaneous consideration and comparison of above- and belowground niches, and suggested the central importance of root-associated fungi to desert plant communities and ecological functions. Understanding the complex host-microbe interactions of desert plants could provide the basis for the exploitation of the plant-fungi associations in manipulation of shrubs' microbiome for desert ecological restoration.

\section{Methods}

Study site and sampling

The study was conducted in the Anxi Extreme Arid Desert of the National Nature Reserve in Gansu Province ( $\left.40^{\circ} 06^{\prime}-40^{\circ} 08^{\prime} \mathrm{N}, 96^{\circ} 17^{\prime}-96^{\circ} 36^{\prime} \mathrm{E}\right)$, Northwest China. This study site is located at the intersection of an Asian temperate desert, an extremely arid desert and a typical desert region companying with a typical continental climate. The average annual temperature is $7.8-10^{\circ} \mathrm{C}$, and the average annual precipitation is no more than $52.0 \mathrm{~mm}$, which is far less than the average annual evaporation of $2754.9 \mathrm{~mm}$ [48]. The soils are dark chestnut and sandy chestnut [100]. The vegetation is dominated by typical super-xerophytes, including Ephedra przewalskii, Reaumuria soongorica, Sympegma regelii, Nitraria sphaerocarpa and Salsola passerina, which is abundant and exhibits a heterogeneous distribution.

Sampling was carried out in July 2019, consisting of collecting leaf, stem, and root samples from three replicated plots. Within each sampling plot, five healthy plants were randomly selected, with each plant individual at least $100 \mathrm{~m}$ away from another individual. Stem samples were collected from the branches of each plant ( 0.1 to $0.6 \mathrm{~cm}$ diameter) at the half-crown level [3]. In addition, all leaves from the sampled offshoot were collected to represent the leaf compartment (except in the case of Ephedra przewalskii). Before collecting the root samples, the upper layer of soil (approximately 1-5 mm) was removed to clear away litter, and the roots were subsequently obtained from a depth of $30 \mathrm{~cm}$ under the canopy of each plant. All samples were collected over a 1-day period to reduce any heterogeneity imparted by the climatic conditions and immediately placed in sterile plastic bags, labelled, and transported to the laboratory in an ice box. The five subsamples collected from each plot were equally merged into one, and a total of 42 plant tissue samples were analysed in this study. All the samples were immediately surface sterilized and stored at $-80^{\circ} \mathrm{C}$ until used for DNA extraction.

Molecular analysis

The plant materials (leaves, stems and roots) were washed with deionized water and surface sterilized by consecutive immersion for $5 \mathrm{~min}$ in $70 \%$ ethanol, $2 \mathrm{~min}$ in 5\% sodium hypochlorite, and $30 \mathrm{~s}$ in $70 \%$ ethanol, followed by three rinses in sterile distilled water. Subsequently, the treated samples were freeze dried using liquid nitrogen and prepared for DNA extraction. The genomic DNA of the endophytic fungi 
from the plant samples was extracted using the Invisorb Spin Plant Mini Kit according to the manufacturer's protocol (Stratec Biomedical AG, Birkenfeld, Germany). The final DNA concentration and purity were determined by a NanoDrop 2000 UV-vis spectrophotometer (Thermo Scientific, Wilmington, USA), and DNA quality was checked with $1 \%$ agarose gel electrophoresis.

The fungal internal transcribed spacer 2 (ITS2) amplicon libraries were generated using a two-step PCR procedure [19]. First, amplification was carried out with the primers ITS1F [101] and ITS4 [102] to generate the entire ITS regions of fungi with a thermocycler PCR system (GeneAmp 9700, ABI, USA). The PCR reactions were performed in triplicate in $20 \mu \mathrm{L}$ mixtures containing $4 \mu \mathrm{L}$ of $5 \times$ FastPfu Buffer, $2 \mu \mathrm{L}$ of $2.5 \mathrm{mM}$ dNTPs, $0.8 \mu \mathrm{L}$ of each primer $(5 \mu \mathrm{M}), 0.4 \mu \mathrm{L}$ of FastPfu Polymerase, and $10 \mathrm{ng}$ of template DNA. The PCRs were conducted using the following programme: $3 \mathrm{~min}$ of denaturation at $95^{\circ} \mathrm{C} ; 27$ cycles of $30 \mathrm{~s}$ at $95^{\circ} \mathrm{C}, 30 \mathrm{~s}$ for annealing at $55^{\circ} \mathrm{C}$, and $45 \mathrm{~s}$ for elongation at $72{ }^{\circ} \mathrm{C}$; and a final extension at $72{ }^{\circ} \mathrm{C}$ for $10 \mathrm{~min}$. The product of the first PCR dilute solution was used as the template for the second PCR under the same conditions as in the first procedure, but the specific primer pair of fITS7 [103] and ITS4 was used for the amplification of the ITS2 regions of fungi. The resulting PCR products were extracted from a 2\% agarose gel and further purified using the AxyPrep DNA Gel Extraction Kit (Axygen Biosciences, Union City, CA, USA) and quantified using a QuantiFluor ${ }^{\text {TM }}$-ST system (Promega, USA) according to the manufacturer's protocol. The purified amplicons were pooled in equimolar amounts and paired-end sequenced $(2 \times 300$ base pairs (bp)) on an Illumina MiSeq platform (Illumina, San Diego, USA) according to the standard protocols of Majorbio Bio-Pharm Technology Co., Ltd. (Shanghai, China).

Bioinformatics processing

Raw FASTQ files were quality filtered with Trimmomatic and merged with FLASH to obtain valid and highquality sequences on the basis of the following criteria: (i) The reads were truncated at any site receiving an average quality score $<20$ over a 50 bp sliding window. (ii) Sequences whose overlap was longer than $10 \mathrm{bp}$ were merged according to their overlap with a mismatch of no more than $2 \mathrm{bp}$. The sequences from each sample were separated according to barcodes (exactly matching) and primers (allowing 2 nucleotide mismatches), and reads containing ambiguous bases were removed. Operational taxonomic units (OTUs) were clustered according to a 97\% similarity cut-off using UPARSE (version 7.0.1090, http://www.drive5.com/uparse/) with a novel 'greedy' algorithm that performs chimera filtering and OTU clustering simultaneously after dereplication and discarding all singletons [104]. The taxonomy of each representative sequence was analysed with the RDP Classifier algorithm (http://rdp.cme.msu.edu/) against the UNITE (version 8.0, https://unite.ut.ee/) database using a confidence threshold of $70 \%[105$, 106]. To eliminate the effects of the different numbers of sequences among the samples on the identified fungal community, the number of sequences per sample was normalized to the smallest sample size using the subsample command in MOTHUR. Subsequently, rarefaction curves were assembled, and the alpha diversity indices of OTU richness, Shannon diversity and evenness were calculated. The relative abundance of specific fungal taxa on the basis of OTU, order and class was defined as the number reads of a particular taxon as a percentage of the number of all reads in a sample [19]. 


\section{Statistical analysis}

All statistical analyses were implemented in $\mathrm{R}$ version 3.5.1. The Shapiro-Wilk test and Bartlett's test were employed to check the normality and homoscedasticity of the data, respectively [15]. As the endophytic fungal OTU richness data did not satisfy the normality of distribution and homogeneity of variance, the effects of plant species and tissue niche on the alpha diversity estimates for the fungal assemblage were examined using the Kruskal-Wallis (KW) test [19], followed by Welch's tests for paired comparisons between samples [107]. The numbers of OTUs that were shared between plants and tissues were visualized using Venn diagrams. The relative abundances of abundant endophytic fungal OTUs in the different plant species and tissues were depicted using the pheatmap function in the pheatmap package in $\mathrm{R}$; then, differential abundance analysis was performed with the KW H test $(P<0.05)$, and STAMP software (v.2.1.3) was used [108]. Nonmetric multidimensional scaling (NMDS) was used to visualize the community composition dissimilarities of the endophytic fungi based on the Bray-Curtis method using the metaMDS command in the vegan package in R. To statistically support the clustering of fungal communities shown in the NMDS plot, the nonparametric ANOSIM test (an analogue of univariate ANOVA) was used to examine significant differences based on 999 permutations [15, 109]. Linear discriminant analysis (LDA) effect size (LEfSe), which can take into account statistical significance and biological relevance, was conducted to identify the OTUs differentially represented between the different species and tissues by using the nonparametric factorial KW sum-rank test and LDA [110, 111]. High LDA scores reflect a significantly higher abundance of certain taxa than that of others.

According to Toju et al. [112], we evaluated the host/tissue-fungus preference based on the interaction specialization index $(d)$ using the 'dfun' function in the R bipartite package [113]. The $d^{\prime}$ 'index measures how strongly a fungus deviates from a random choice among plant partners that are available at a study site [114]. Considering the difficulty of estimating the host preferences of rare fungi, the d' estimates of the abundant endophytic fungal OTUs (> 1000 reads) were used $[19,112,114]$. Firstly, the sample data matrix was binarized to a sample-level matrix (present-absent data) and then converted into a specieslevel matrix, in which rows denote plant species, columns represent fungal OTUs, and cell entries indicate the number of samples from which respective combinations of plants and fungi were observed. Subsequently, the randomized species-level matrices were obtained based on 1000 permutations by shuffling the plant species labels in the sample fungal OTU matrix. The $d^{\prime}$ 'value of each fungal OTU [115] was standardized as follows: standardized $d^{\prime}=$ [ $d^{\prime}$ observed - Mean ( $d$ 'randomized)]/SD ( $d^{\prime}$ 'randomized), where $d$ 'observed is the $d^{\prime}$ 'estimate of the original data, and Mean ( $d$ 'randomized) and SD ( $d$ 'randomized) are the mean and standard deviation of the d' values of the randomized data matrices. The standardized $d$ 'value was also calculated for each plant species based on the original and randomized data matrices mentioned above. Additionally, the two-dimensional preferences (2DP) seen in a pair of a plant species ( $I)$ and a fungal OTU ( $)$ ) were quantified based on the species-level original and randomized matrices to evaluate to what extent each pair of each plant-fungus association was observed (counts) more or less frequently than would be expected by chance. $2 D P(i, j)=\left[N_{\text {observed }}(i, j)\right.$ - Mean $\left.\left(N_{\text {randomized }}(i, j)\right)\right] / S D$ $\left(N_{\text {randomized }}(i, j)\right)$, where $N_{\text {observed }}(i, j)$ is the number of the samples from which a pair of a plant-fungal 
OTU association was observed in the original data, and Mean $\left(N_{\text {randomized }}(i, j)\right)$ and SD $\left(N_{\text {randomized }}(i, j)\right)$ are the mean and the standard deviation of the number of samples for the focal plant-fungal OTU pair across randomized matrices. The $P$ value obtained from the preference analysis was adjusted based on the false discovery rate (FDR) [116]. Similarly, tissue $\times$ fungal OTU matrix were carried out, and the standardized $d^{\prime}$ value of both each niche tissues and each fungal species was also calculated, as well as the2DP estimators.

Network analysis was performed to identify the microbial co-occurrence patterns across the three plant tissues associated with the five plants, respectively. Alternatively, we explored the interspecies relationship between above- and belowground niches by constructing a total co-occurrence network pattern using the overall database. Before network construction, we removed very rare OTUs and the abundant endophytic fungal OTUs (> 1000 reads) were used $[15,88]$. Spearman's rank correlations were calculated with all possible OTU pairs and robust correlations with correlation coefficient above 0.5 and statistical significance $(P<0.01)$ were noted [117]. The nodes of the network represent individual OTUs that have at least one significant co-occurrence relationship with other OTUs. The networks were explored and visualized with Cytoscape v3.5.1, and NetworkAnalyzer tool was used to calculate network topology parameters [118]. Structural attributes of networks such as the number of nodes and edges, graph density, network connectivity, the clustering coefficient, network centralization, characteristic path length and network heterogeneity were determined [119]. Modular structure and groups of highly interconnected nodes were analyzed using the MCODE application with standard parameters $[118,120]$. A module is a group of nodes connected more densely to each other than to other nodes outside the group. Possible keystone species were those that demonstrated the higher degree values [121].

\section{Additional files}

Additional file 1: Table S1. Molecular identification of endophytic fungi (>1000 reads) at a $97 \%$ sequence identity level. (XLSX $42 \mathrm{~kb}$ )

Additional file 2: Figure S1. Rarefaction curves for the observed endophytic fungal operational taxonomic units (OTUs). Rarefaction curves were assembled showing the number of OTUs, defined at the $97 \%$ sequence similarity cut-off in MOTHUR, relative to the number of total sequences. RS, Reaumuria soongorica; SR, Sympegma regelii; NS, Nitraria sphaerocarpa; SP, Salsola passerina; EP, Ephedra przewalskii. S, stem; L, leaf; R, root. (PDF 178 kb) Figure S2. Operational taxonomic unit (OTUs) distribution across host plants and tissue niches. Venn diagram displaying the overlap in OTUs composition between the different hosts and plant niches. RS, Reaumuria soongorica; SR, Sympegma regelii; NS, Nitraria sphaerocarpa; SP, Salsola passerina; EP, Ephedra przewalskii. S, stem; L, leaf; R, root. (PDF $437 \mathrm{~kb}$ ) Figure S3. Differential abundance analysis of abundant fungal OTUs. Kruskal-Wallis $\mathrm{H}$ test were performed to compare the significant differences of OTUs abundance among plant species and tissues. Only differentially abundant OTUs $(P<0.05)$ are shown. RS, Reaumuria soongorica; SR, Sympegma regelii, NS, Nitraria sphaerocarpa; SP, Salsola passerina; EP, Ephedra przewalskii. S, stem; L, leaf; R, root. (PDF 827 kb) Figure S4. Modular groups of highly interconnected nodes. MCODE analysis 
showing the sub-networks with highest node scores in different plant niches and the total networks. (PDF $491 \mathrm{~kb})$

Additional file 3: Table S2. Structural attributes of networks obtained through network analysis for different plant niches (stem, leaf and root) and the total networks. Table S3. The ten keystone species in each plant niches, characterized by their number of connections, shown by the number of total degrees, as either positive (+) or negative (-), and their relative abundance (\%). (DOCX $27 \mathrm{~kb}$ )

\section{Declarations}

\section{Acknowledgements}

We greatly appreciate the support of Anxi Extreme Arid Desert of the National Nature Reserve for their invaluable assistance on this experiment. We thank the students Yedong Li, Kaixun Zhang, Dongdong Zhang, Yiting Hou and Wenbin Wang for sampling and laboratory work.

\section{Funding}

This work was financially supported by the National Natural Science Foundation of China (project no. 31770561 and 31800345) and the National Science Foundation of Hebei Province, China (C2020201043).

\section{Availability of data and materials}

The raw data sequences wered eposited in the NCBI Sequence ReadArchive (SRA) under the Bioproject number PRJNA681429 and Bio Sample accession numbers SAMN16953820 to SAMN16953861.

\section{Authors' contributions}

XLH and YLZ designed the experiment; YLZ and JQL collected the samples; XL, JYY and LLZ performed the laboratory work; $\mathrm{XLH}, \mathrm{YLZ}$ and $\mathrm{XL}$ analyzed the data and wrote the manuscript. All authors read and approved the final manuscript.

\section{Ethics approval and consent to participate}

Not applicable.

\section{Consent for publication}

Not applicable.

\section{Competing interests}

The authors declare that they have no competing interests. 


\section{Author details}

${ }^{1}$ School of Life Sciences, Hebei University, Baoding 071002, People's Republic of China.

2 Institute of Life Sciences and Green Development, Hebei University, Baoding 071002, People's Republic of China.

\section{References}

1. Hassani MA, Duran P, Hacquard S. Microbial interactions within the plant holobiont. Microbiome. 2018;6:58. http://dx.doi.org/10.1186/s40168-018-0445-0.

2. Trivedi P, Leach JE, Tringe SG, Sa T, Singh BK. Plant-microbiome interactions: from community assembly to plant health. Nat Rev Microbiol. 2020;18:607-21. https://dx.doi.org/10.1038/s41579020-0412-1.

3. Beckers B, Op De Beeck M, Weyens N. Weyens N, Boerjan W, Vangronsveld J. Structural variability and niche differentiation in the rhizosphere and endosphere bacterial microbiome of field-grown poplar trees. Microbiome. 2017;5:25. https://dx.doi.org/10.1186/s40168-017-0241-2.

4. Elizabeth Arnold A. Understanding the diversity of foliar endophytic fungi: progress, challenges, and frontiers. Fungal Biol Rev. 2007;21:51-6. https://dx.doi.org/10.1016/j.fbr.2007.05.003.

5. Lucero ME, Barrow JR, Osuna P, Reyes I. Plant-fungal interactions in arid and semi-arid ecosystems: Large-scale impacts from microscale processes. J Arid Environ. 2006;65:276-84. https://dx.doi.org/10.1016/j.jaridenv.2005.08.014.

6. González-Teuber M, Vilo C, Bascuñán-Godoy L. Molecular characterization of endophytic fungi associated with the roots of Chenopodium quinoa inhabiting the Atacama Desert, Chile. Genom Data. 2017;11:109-12. https://dx.doi:10.1016/j.gdata.2016.12.015.

7. Rosa LH, Almeida Vieira Mde L, Santiago IF, Rosa CA. Endophytic fungi community associated with the dicotyledonous plant Colobanthus quitensis (Kunth) Bartl. (Caryophyllaceae) in Antarctica. FEMS Microbiol Ecol. 2010;73:178-89. https://dx.doi:10.1111/j.1574-6941.2010.00872.x.

8. U'Ren JM, Lutzoni F, Miadlikowska J, Laettsch AD, Arnold AE. Host and geographic structure of endophytic and endolichenic fungi at a continental scale. Am J Bot. 2012;99:898-914. https://dx.doi:10.3732/ajb.1100459.

9. Murgia M, Fiamma M, Barac A, Deligios M, Mazzarello V, Paglietti B, et al. Biodiversity of fungi in hot desert sands. Microbiology Open. 2019;1:e00595. https://doi.org/10.1002/mbo3.595.

10. Yang J, Kloepper JW, Ryu C. Rhizosphere bacteria help plants tolerate abiotic stress. Trends Plant Sci. 2009;14:1-4. http://dx.doi.org/10.1016/j.tplants.2008.10.004.

11. Marasco R, Rolli E, Ettoumi B, Vigani G, Mapelli F, Borin S, Abou-Hadid AF, El-Behairy UA, Sorlini C, Cherif A, Zocchi G, Daffonchio D. A drought resistance-promoting microbiome is selected by root system under desert farming. Plos One. 2012;7:e48479.

http://dx.doi.org/10.1371/journal.pone.0048479. 
12. Massimo NC, Nandi Devan MM, Arendt KR, Wilch MH, Riddle JM, Furr SH, Arnold AE. Fungal endophytes in aboveground tissues of desert plants: infrequent in culture, but highly diverse and distinctive symbionts. Microb Ecol. 2015;70:61-76. https://dx.doi:10.1007/s00248-014-0563-6.

13. Põlme S, Bahram M, Jacquemyn H, Kennedy P, Kohout P, Moora M, Tedersoo L. Host preference and network properties in biotrophic plant-fungal associations. New Phytol. 2017;217:1230-9. https://dx.doi:10.1111/nph.14895.

14. Lenoir I, Fontaine J, Lounès-Hadj Sahraoui A. Arbuscular mycorrhizal fungal responses to abiotic stresses: a review. Phytochemistry. 2016;123:4-15. https://dx.doi:10.1016/j.phytochem.2016.01.002.

15. Durand A, Maillard F, Foulon J, Gweon HS, Valot B, Chalot M. Environmental metabarcoding reveals contrasting belowground and aboveground fungal communities from Poplar at a $\mathrm{Hg}$ phytomanagement Site. Mol Ecol. 2017;74:795-809. https://dx.doi:10.1007/s00248-017-0984-0.

16. Martin FM, Uroz S, Barker DG. Ancestral alliances: Plant mutualistic symbioses with fungi and bacteria. Science. 2017;356:eaad4501. https://dx.doi:10.1126/science.aad4501.

17. Balint M, Bartha L, O’Hara RB, Olson MS, Otte J, Pfenninger M, Robertson AL, Tiffin P, Schmitt I. Relocation, highlatitude warming and host genetic identity shape the foliar fungal microbiome of poplars. Mol Ecol. 2015;24:235-48. https://dx.doi:10.1111/mec.13018.

18. Xiong C, Zhu YG, Wang JT, Singh B, Han LL, Shen JP, Li PP, Wang GB, Wu CF, Ge AH, Zhang LM, He JZ. Host selection shapes crop microbiome assembly and network complexity. New Phytol. 2020. https://dx.doi. 10.1111/nph.16890.

19. Yao H, Sun X, He C, Maitra P, Li XC, Guo LD. Phyllosphere epiphytic and endophytic fungal community and network structures differ in a tropical mangrove ecosystem. Microbiome. 2019;7:57. https://dx.doi:10.1186/s40168-019-0671-0.

20. Martínez-García LB, Armas C, Miranda J, de D, Padilla, Pugnaire FM. FI. Shrubs influence arbuscular mycorrhizal fungi communities in a semi-arid environment. Soil Biol Biochem. 2011;43:682-9. https://dx.doi:10.1016/j.soilbio.2010.12.006.

21. White JF, Torres MS, Johnson H, Irizarry I, Tadych M. A Functional view of plant microbiomes: endosymbiotic systems that enhance plant growth and survival. In: Verma V, Gange A, editors. Advances in Endophytic Research. New Delhi: Springer; 2014. pp. 425-39. https://doi.org/10.1007/978-81-322-1575-2_21.

22. Rodriguez RJ, Woodward C, Redman RS. Adaptation and survival of plants in high stress habitats via fungal endophyte conferred stress tolerance. In: Seckbach J, Grube M, editors. Symbioses and Stress. Cellular Origin, Life in Extreme Habitats and Astrobiology. 17. Dordrecht: Springer; 2010. pp. 461-76. https://doi.org/10.1007/978-90-481-9449-0_23.

23. Bonito G, Reynolds H, Robeson MS, Nelson J, Hodkinson BP, Tuskan G, Vilgalys R. Plant host and soil origin influence fungal and bacterial assemblages in the roots of woody plants. Mol Ecol. 2014;23:3356-70. https://dx.doi:10.1111/mec.12821. 
24. Jacquemyn H, Brys R, Waud M, Busschaert P. Lievens B. Mycorrhizal networks and coexistence in species-rich orchid communities. New Phytol. 2015;206:1127-34. https://dx.doi:10.1111/nph.13281.

25. Davison J, Opik M, Daniell T, Moora M, Zobel M. Arbuscular mycorrhizal fungal communities in plant roots are not random assemblages. FEMS Microbiol Ecol. 2011;78:103-15. http://dx.doi.org/10.1111/j.1574-6941.2011.01103.x.

26. Montesinos-Navarro A, Segarra-Moragues JG, Valiente-Banuet A, Verdu M. The network structure of plant-arbuscular mycorrhizal fungi. New Phytol. 2012;194:536-47. http://dx.doi.org/10.1111/j.14698137.2011.04045.x.

27. Coleman-Derr D, Desgarennes D, Fonseca-Garcia C, Gross S, Clingenpeel S, Woyke T, et al. Plant compartment and biogeography affect microbiome composition in cultivated and native Agave species. New Phytol. 2016;209:798-811. http://dx.doi.org/10.1111/nph.13697.

28. Fonseca-García C, Coleman-Derr D, Garrido E, Visel A, Tringe SG, Partida-Martínez LP. The cacti microbiome: interplay between habitat-filtering and host-specificity. Front Microbiol. 2016;7:150. http://dx.doi.org/10.3389/fmicb.2016.00150.

29. Zheng Y, Gong X. Niche differentiation rather than biogeography shapes the diversity and composition of microbiome of Cycas panzhihuaensis. Microbiome. 2019;7:152. https://doi.org/10.1186/s40168-019-0770-y.

30. Jones DL, Nguyen C, Finlay RD. Carbon flow in the rhizosphere: carbon trading at the soil-root interface. Plant Soil. 2009;321:5-33. https://doi.org/10.1007/s11104-009-9925-0.

31. Qian X, Li H, Wang Y, Wu B, Wu M, Chen L, et al. Leaf and root endospheres harbor lower fungal diversity and less Complex fungal co-occurrence patterns than rhizosphere. Front Microbiol. 2019;10:1015. https://doi:10.3389/fmicb.2019.01015.

32. Toju H, Kurokawa H, Kenta T. Factors influencing leaf- and root-associated communities of bacteria and fungi across 33 plant orders in a grassland. Front Microbiol. 2019;10:241. https://doi.org/10.3389/fmicb.2019.00241.

33. Guevara-Araya MJ, Vilo C, Urzúa A, González-Teuber M. Differences in community composition of endophytic fungi between above- and below-ground tissues of Aristolochia chilensis in an arid ecosystem. Rev Chil de Hist Nat. 2020;93:3. https://doi.org/10.1186/s40693-020-00091-y.

34. Bai Y, Müller DB, Srinivas G, Garrido-Oter R, Potthoff E, Rott M, et al. Functional overlap of the Arabidopsis leaf and root microbiota. Nature. 2015;528:364-9. http://dx.doi.org/10.1038/nature16192.

35. Boer W, de Folman LB, Summerbell RC, Boddy L. Living in a fungal world: impact of fungi on soil bacterial niche development. FEMS Microbiol Rev. 2005;29:795-811. http://doi:10.1016/j.femsre.2004.11.005.

36. Klosterman SJ, Subbarao KV, Kang S, Veronese P, Gold SE, Thomma BPHJ, et al. Comparative genomics yields insights into niche adaptation of plant vascular wilt pathogens. PLoS Pathog. 2011;7:e1002137. http://doi:10.1371/journal.ppat.1002137. 
37. He D, Shen W, Eberwein J, Zhao Q, Ren L, Wu QL. Diversity and co-occurrence network of soil fungi are more responsive than those of bacteria to shifts in precipitation seasonality in a subtropical forest. Soil Biol Biochem. 2017;115:499-510. http://doi:10.1016/j.soilbio.2017.09.023.

38. Freilich S, Kreimer A, Meilijson I, Gophna U, Sharan R, Ruppin E. The large-scale organization of the bacterial network of ecological co-occurrence interactions. Nucleic Acids Res. 2010;38:3857-68. http://dx.doi.org/10.1093/nar/gkq118.

39. Fuhrman JA. Microbial community structure and its functional implications. Nature. 2009;459:1939. http://dx.doi.org/10.1038/nature08058.

40. Banerjee S, Thrall PH, Bissett A, van der Heijden MGA, Richardson AE. Linking microbial cooccurrences to soil ecological processes across a woodland-grassland ecotone. Ecol Evol. 2018;8:8217-30. https://doi.org/10.1002/ece3.4346.

41. Xue L, Ren H, Brodribb TJ, Wang J, Yao X, Li S. Long term effects of management practice intensification on soil microbial community structure and co-occurrence network in a non-timber plantation. Forest Ecol Manag. 2020;459:117805. https://doi:10.1016/j.foreco.2019.117805.

42. Toju H, Kishida O, Katayama N, Takagi K. Networks depicting the fine-scale co-occurrences of fungi in soil horizons. PLoS One. 2016;11:e0165987. https://doi:10.1371/journal.pone.0165987.

43. De Menezes AB, Richardson AE, Thrall PH. Linking fungal-bacterial co-occurrences to soil ecosystem function. Curr Opin Microbiol. 2017;37:135-41. https://doi:10.1016/j.mib.2017.06.006.

44. Lu L, Yin S, Liu X, Zhang W, Gu T, Shen Q, et al. Fungal networks in yield-invigorating and -debilitating soils induced by prolonged potato monoculture. Soil Biol Biochem. 2013;65:186-94. http://dx.doi.org/10.1016/j.soilbio.2013.05.025.

45. Karimi B, Maron PA, Chemidlin-Prevost BN, Bernard N, Gilbert D, Ranjard L. Microbial diversity and ecological networks as indicators of environmental quality. Environ Chem Lett. 2017;15:265-81. https://doi.org/10.1007/s10311-017-0614-6.

46. Wang JJ, Qiang W, Liu HY, Ge JL, Zuo YL, He XL. Effects of plants pecies on diversity of arbuscular mycorrhizal fungi in extremely arid desert environment. Mycosystema. 2017;36:861-9.

47. Lugo MA, Reinhart KO, Menoyo E, Crespo EM, Urcelay C. Plant functional traits and phylogenetic relatedness explain variation in associations with root fungal endophytes in an extreme arid environment. Mycorrhiza. 2014;25:85-95. http://dx.doi.org/10.1007/s00572-014-0592-5.

48. Rodrigues A, Bacci M, Mueller UG, Ortiz A, Pagnocca FC. Microfungal "weeds" in the leafcutter ant symbiosis. Microb Ecol. 2008;56:604-14. http://dx.doi.org/10.1007/s00248-008-9380-0.

49. Yu J, Xue ZK, He XL, Liu CM, Steinberger Y. Shifts in composition and diversity of arbuscular mycorrhizal fungi and glomalin contents during revegetation of desertified semiarid grassland. Appl Soil Ecol. 2017;115:60-7. http://dx.doi.org/10.1016/j.apsoil.2017.03.015.

50. Xie LL, He XL, Wang K, Hou LF, Sun Q. Spatial dynamics of dark septate endophytes in the roots and rhizospheres of Hedysarum scoparium in northwest China and the influence of edaphic variables. Fungal Ecol. 2017;26:135-43. http://dx.doi.org/10.1016/j.funeco.2017.01.007. 
51. Li X, He C, He XL, Su F, Hou LF, Ren Y, et al. Dark septate endophytes improve the growth of host and non-host plants under drought stress through altered root development. Plant Soil. 2019;439:25972. http://dx.doi.org/10.1007/s11104-019-04057-2.

52. Hou LF, He XL, Li X, Wang SJ, Zhao LL. Species composition and colonization of dark septate endophytes are affected by host plant species and soil depth in the Mu Us sandland, northwest China. Fungal Ecol. 2019;39:276-84. http://dx.doi.org/10.1016/j.funeco.2019.01.001.

53. Qiang W, He XL, Wang JJ, Zhao LL. Temporal and spatial variation of arbuscular mycorrhizal fungi under the canopy of Hedysarum scoparium in the northern desert, China. AppL Soil Ecol. 2019;136:139-47. http://dx.doi.org/10.1016/j.apsoil.2019.01.003.

54. Zuo YL, Su F, He XL, Li M. Colonization by dark septate endophytes improves the growth of Hedysarum scoparium under multiple inoculum levels. Symbiosis. 2020. http://doi:10.1007/s13199020-00713-9.

55. Porras-Alfaro A, Herrera J, Sinsabaugh RL, Odenbach KJ, Lowrey T, Natvig DO. Novel root fungal consortium associated with a dominant desert grass. Appl Environ Microb. 2008;74:2805-13. http://doi:10.1128/AEM.02769-07.

56. Sangamesh MB, Jambagi S, Vasanthakumari MM, Shetty NJ, Kolte $\mathrm{H}$, et al. Thermotolerance of fungal endophytes isolated from plants adapted to the Thar Desert, India. Symbiosis. 2017;75:13547. http://doi:10.1007/s13199-017-0527-y.

57. Hamm P, Mueller RC, Kuske CR, Porras-Alfaro A. Keratinophilic fungi: specialized fungal communities in a desert ecosystem identified using cultured-based and Illumina sequencing approaches. Microbiol Res. 2020; 126530. http://doi:10.1016/j.micres.2020.126530.

58. Selbmann L, Egidi E, Isola D, Onofri S, Zucconi L, de Hoog GS, et al. Biodiversity, evolution and adaptation of fungi in extreme environments. Plant Biosyst. 2013;147:237-46. http://doi:10.1080/11263504.2012.753134.

59. Sun Y, Zhang Y, Feng W, Qin S, Liu Z. Revegetated shrub species recruit different soil fungal assemblages in a desert ecosystem. Plant Soil. 2019;435:81-93. http://doi:10.1007/s11104-0183877-1.

60. Masumoto S, Tojo M, Imura S, Herrero ML, Uchida M. Occurrence pattern of the parasitic fungus Rhytisma polare (Ascomycota) on the polar willow (Salix polaris) under limited water conditions in a high-Arctic semi-desert. Polar Biol. 2018;41:1105-10. http://doi:10.1007/s00300-018-2269-6.

61. Jia T, Wang R, Fan X, Chai B. A comparative study of fungal community structure, diversity and richness between the soil and the phyllosphere of native grass species in a copper tailings dam in Shanxi Province, China. Appl Sci. 2018;8:1297. http://dx.doi.org/10.3390/app8081297.

62. Bálint M, Bartha L, O'Hara RB, Olson MS, Otte J, Pfenninger M, et al. Relocation, high-latitude warming and host genetic identity shape the foliar fungal microbiome of poplars. Mol Ecol. 2015; 24: 235-48. https://doi.org/10.1111/mec. 13018.

63. Dissanayake AJ, Purahong W, Wubet T, Hyde KD, Zhang W, Xu HY, et al. Direct comparison of culturedependent and culture-independent molecular approaches reveal the diversity of fungal endophytic 
communities in stems of grapevine (Vitis vinifera). Fungal Divers. 2018;90:85-107. https://doi.org/10.1007/s13225-018-0399-3.

64. Knapp DG, Kovács GM, Zajta E, Groenewald JZ, Crous PW. Dark septate endophytic pleosporalean genera from semiarid areas. Persoonia. 2015;35:87-100. http://dx.doi.org/10.3767/003158515X687669.

65. Foster KR, Schluter J, Coyte KZ, Rakoff-Nahoum S. The evolution of the host microbiome as an ecosystem on a leash. Nature. 2017;548:43-51. http://dx.doi.org/10.1038/nature23292.

66. Lau MK, Arnold AE, Johnson NC. Factors influencing communities of fungal endophytes in riparian woody plants. Fungal Ecol. 2013;6:365-78. http://dx.doi:10.1016/j.funeco.2013.06.003.

67. Turner TR, James EK, Poole PS. The plant microbiome. Genom Biol. 2013;14:1-10. http://dx.doi.org/10.1186/gb-2013-14-6-209.

68. Zarraonaindia I, Owens SM, Weisenhorn P, West K, Hampton-Marcell J, Lax S, et al. The soil microbiome influences grapevine-associated microbiota. MBio. 2015;6:e02527-14. https://doi:10.1128/mBio.02527-14.

69. Bulgarelli D, Rott M, Schlaeppi K, Ver L, van Themaat E, Ahmadinejad N, Assenza F, et al. Revealing structure and assembly cues for Arabidopsis root-inhabiting bacterial microbiota. Nature. 2012;488:91-5. https://doi:10.1038/nature11336.

70. Lundberg DS, Lebeis SL, Paredes SH, Yourstone S, Gehring J, Malfatti S, et al. Defning the core Arabidopsis thaliana root microbiome. Nature. 2012;488:86-90. https://doi.org/10.1038/nature11237.

71. Vincent JB, Weiblen GD, May G. Host associations and beta diversity of fungal endophyte communities in New Guinea rainforest trees. Mol Ecol. 2016;25:825-41. https://doi.org/10.1111/mec.13510.

72. Larkin BG, Hunt LS, Ramsey PW. Foliar nutrients shape fungal endophyte communities in Western white pine (Pinus monticola) with implications for white-tailed deer herbivory. Fungal Ecol. 2012;5:252-60. https://doi.org/10.1016/j.funeco.2011.11.002.

73. Sun X, Ding Q, Hyde KD, Guo LD. Community structure and preference of endophytic fungi of three woody plants in a mixed forest. Fungal Ecol. 2012;5:624-32. https://doi:10.1016/j.funeco.2012.04.001.

74. Zhou D, Hyde KD. Host-specificity, host-exclusivity, and host-recurrence in saprobic fungi. Mycol Res. 2001;105:1449-57. https://doi:10.1017/s0953756201004713.

75. Edwards J, Johnson C, Santos-Medellín C, Lurie E, Podishetty NK, Bhatnagar S, et al. Structure, variation, and assembly of the root-associated microbiomes of rice. Proc Natl Acad Sci. 2015;112:E911-20. https://doi:10.1073/pnas.1414592112.

76. Suryanarayanan TS, Thirunavukkarasu N, Govindarajulu MB, Gopalan V. Fungal endophytes: an untapped source of biocatalysts. Fungal Diver. 2012;54:19-30. https://doi:10.1007/s13225-0120168-7. 
77. Rodriguez RJ, Redman RS. Fungal Life-styles and ecosystem dynamics: biological aspects of plant pathogens, plant endophytes and saprophytes. Adv Bot Res. 1997;24:169-93. https://doi:10.1016/S0065-2296(08)60073-7.

78. Tardif S, Yergeau É, Tremblay J, Legendre P, Whyte LG, Greer CW. The willow microbiome is influenced by soil petroleum-hydrocarbon concentration with plant compartment-specific effects. Front Microbiol. 2016;7:1363. https://doi:10.3389/fmicb.2016.01363.

79. Herrera J, Khidir HH, Eudy DM, Porras-Alfaro A, Natvig DO, Sinsabaugh RL. Shifting fungal endophyte communities colonize Bouteloua gracilis: effect of host tissue and geographical distribution. Mycologia. 2010;102:1012-26. http://dx.doi.org/10.3852/09-264.

80. Schardl CL, Leuchtmann A, Spiering MJ. Symbioses of grasses with seedborne fungal endophytes. Annu Rev Plant Boil. 2004;55:315-40. http://dx.doi.org/10.1146/annurev.arplant.55.031903.141735.

81. Tan YY, Spiering MJ, Scott V, Lane GA, Christensen MJ, Schmid J. In planta regulation of extension of an endophytic fungus and maintenance of high metabolic rates in its mycelium in the absence of apical extension. Appl Environ Microb. 2001;67:5377-83.

http://dx.doi.org/10.1128/AEM.67.12.5377-5383.2001.

82. Wearn JA, Sutton BC, Morley NJ, Gange AC. Species and organ specificity of fungal endophytes in herbaceous grassland plants. J Ecol. 2012;100:1085-92. http://dx.doi.org/10.1111/j.13652745.2012.01997.x.

83. Wu L, Han T, Li W, Jia M, Xue L, Rahman K, et al. Geographic and tissue influences on endophytic fungal communities of Taxus chinensis var. mairei in China. Curr Microbiol. 2013;66:40-8. https://doi.org/10.1007/s00284-012-0235-z.

84. Knapp DG, Kovács GM. Interspecific metabolic diversity of root-colonizing endophytic fungi revealed by enzyme activity tests. FEMS Microbiol Ecol. 2016;92:fiw190. https://doi.org/10.1093/femsec/fiw190.

85. Petrini O, Sieber TN, Toti L, Viret O. Ecology, metabolite production, and substrate utilization in endophytic fungi. Nat Toxins. 1993;1:185-96. http://dx.doi.org/10.1002/nt.2620010306.

86. Bais HP, Weir TL, Perry LG, Gilroy S, Vivanco JM. The role of root exudates in rhizosphere interactions with plants and other organisms. Annu Rev Plant Biol. 2006;57:233-66. https://doi:10.1146/annurev.arplant.57.032905.105159.

87. Vorholt JA. Microbial life in the phyllosphere. Nat Rev Microbiol. 2012;10:828-40. http://dx.doi.org/10.1038/nrmicro2910.

88. Weiss S, Van Treuren W, Lozupone C, Faust K, Friedman J, Deng Y, et al. Correlation detection strategies in microbial data sets vary widely in sensitivity and precision. ISME J. 2016;10:1669-81. http://doi:10.1038/ismej.2015.235.

89. Mandakovic D, Rojas C, Maldonado J, Latorre M, Travisany D, Delage E, et al. Structure and cooccurrence patterns in microbial communities under acute environmental stress reveal ecological factors fostering resilience. Sci Rep-UK. 2018;8:5875. http://doi:10.1038/s41598-018-23931-0. 
90. Mapelli F, Marasco R, Fusi M, Scaglia B, Tsiamis G, Rolli E, et al. The stage of soil development modulates rhizosphere effect along a High Arctic desert chronosequence. ISME J. 2018;12:1188-98. http://dx.doi.org/10.1038/s41396-017-0026-4.

91. Eldridge DJ, Woodhouse JN, Curlevski NJA, Hayward M, Brown MV, Neilan BA. Soil-foraging animals alter the composition and co-occurrence of microbial communities in a desert shrubland. ISME J. 2015;9:2671-81. http://dx.doi.org/10.1038/ismej.2015.70.

92. Bissett A, Brown MV, Siciliano SD, Thrall PH. Microbial community responses to anthropogenically induced environmental change: towards a systems approach. Ecol Lett. 2013;16:128-39. http://dx.doi.org/10.1111/ele.12109.

93. Xue L, Ren H, Brodribb TJ, Wang J, Yao XH, Li S. Long term effects of management practice intensifcation on soil microbial community structure and co-occurrence network in a non-timber plantation. Forest Ecol Manag. 2020;459:117805. https://doi.org/10.1016/j.foreco.2019.117805.

94. Lu L, Yin S, Liu X, Zhang W, Gu T, Shen Q, et al. Fungal networks in yield-invigorating and -debilitating soils induced by prolonged potato monoculture. Soil Biol Biochem. 2013;65:186-94. https://doi:10.1016/j.soilbio.2013.05.025.

95. Resquín-Romero G, Cabral-Antúnez C, Sarubbi-Orue H, Garrido-Jurado I, Valverde-García P, Schade M, et al. Virulence of Metarhizium brunneum (Ascomycota: Hypocreales) strains against stinkbugs Euschistus heros and Dichelops furcatus (Hemiptera: Pentatomidae). J Econ Entomol. 2020;113:2540-5. https://doi.org/10.1093/jee/toaa150.

96. White RL, Geden CJ, Kaufman PE. Exposure timing and method affect Beauveria bassiana (Hypocreales: Cordycipitaceae) efficacy against house fly (Diptera: Muscidae) Larvae. J Med Entomol. 2020; tjaa156. https://doi:10.1093/jme/tjaa156.

97. Batta Y. Entomopathogenic effect of Trichothecium roseum (Pers.) link (Hypocreales: Ascomycota) against Pauropsylla buxtoni (Psylloidea: Hemiptera) infesting Ficus carica leaves and its potential use as biocontrol agent of the insect. J Appl Microbiol. 2020;129:400-10. https://doi:10.1111/jam.14613.

98. Harris R. Effect of water potential on microbial growth and activity. In: Parr J, Gardner W, Elliott L, editors. Water Potential Relations in Soil Microbiology. Madison: Soil Science Society of America; 1981. pp. 23-95.

99. Agler MT, Ruhe J, Kroll S, Morhenn C, Kim ST, Weigel D, et al. Microbial hub taxa link host and abiotic factors to plant microbiome variation. PLoS Biol. 2016;14:e1002352. https://doi.org/10.1371/journal.pbio.1002352.

100. Kimmins JP. Forest Ecology. 258. Beijing: China Forestry Publishing House; 2005. pp. 17-43.

101. Gardes M, Bruns TD. ITS primers with enhanced specificity for Basidiomycetes-application to the identification of mycorrhizae and rusts. Mol Ecol. 1993;2:113-8. https://doi.org/10.1111/j.1365294X.1993.tb00005.x.

102. White TJ, Bruns T, Lee S, Taylor JW. Amplification and direct sequencing of fungal ribosomal RNA genes for phylogenetics. In: Innis M, Gelfand D, Sninsky J, White T, editors. PCR protocols: a guide to 
methods and applications. New York: Academic; 1990. pp. 315-22.

103. Ihrmark K, Bödeker ITM, Cruz-Martinez K, Friberg H, Kubartova A, Schenck J, et al. New primers to amplify the fungal ITS2 region-evaluation by 454-sequencing of artificial and natural communities. FEMS Microbiol Ecol. 2012;82:666-77. https://doi.org/10.1111/j.1574-6941.2012.01437.x.

104. Edgar RC. UPARSE: highly accurate OTU sequences from microbial amplicon reads. Nat Methods. 2013;10:996-8. https://doi.org/10.1038/NMETH.2604.

105. Kõljalg U, Nilsson RH, Abarenkov K, Tedersoo L, Taylor AFS, Bahram M, et al. Towards a unified paradigm for sequence-based identification of fungi. Mol Ecol. 2013;22:5271-7. https://doi:10.1111/mec.12481.

106. Dickie IA. Insidious effects of sequencing errors on perceived diversity in molecular surveys. New Phytol. 2010;188:916-8. https://doi:10.1111/j.1469-8137.2010.03473.x.

107. Pérez-Jaramillo JE, de Hollander M, Ramírez CA, Mendes R, Raaijmakers JM, Carrión VJ. Deciphering rhizosphere microbiome assembly of wild and modern common bean (Phaseolus vulgaris) in native and agricultural soils from Colombia. Microbiome. 2019;7:114. https://doi.org/10.1186/s40168-0190727-1.

108. Parks DH, Tyson GW, Hugenholtz P, Beiko RG. STAMP: statistical analysis of taxonomic and functional profiles. Bioinformatics. 2014;30:3123-4. https://doi:10.1093/bioinformatics/btu494.

109. Clarke KR, Somerfield PJ, Chapman MG. On resemblance measures for ecological studies, including taxonomic dissimilarities and a zero-adjusted Bray-Curtis coefficient for denuded assemblages. $J$ Exp Mar Biol Ecol. 2006;330:55-80. https://doi.org/10.1016/j.jembe.2005.12.017.

110. Segata N, Izard J, Waldron L, Gevers D, Miropolsky L, Garrett WS, et al. Metagenomic biomarker discovery and explanation. Genome Biol. 2011;12:R60. https://doi:10.1186/gb-2011-12-6-r60.

111. Guerrero-Preston R, Godoy-Vitorino F, Jedlicka A, Rodríguez-Hilario A, González H, Bondy J, et al. 16S rRNA amplicon sequencing identifies microbiota associated with oral cancer, human papilloma virus infection and surgical treatment. Oncotarget. 2016;7:51320-34.

https://doi:10.18632/oncotarget.9710.

112. Toju $\mathrm{H}$, Tanabe AS, Ishii HS. Ericaceous plant-fungus network in a harsh alpine-subalpine environment. Mol Ecol. 2016;25:3242-57. https://doi.org/10.1111/mec.13680.

113. Dormann CF, Fründ J, Blüthgen N, Gruber B. Indices, graphs and null models: analyzing bipartite ecological networks. The Open Ecol J. 2009;2:7-24. https://doi.org/10.2174/1874213000902010007.

114. Toju H, Yamamoto S, Sato $H$, Tanabe AS. Sharing of diverse mycorrhizal and root-endophytic fungi among plant species in an oak dominated cool-temperate forest. PLoS One. 2013;8:e78248. https://doi:10.1371/journal.pone.0078248.

115. Blüthgen N, Menzel F, Hovestadt T, Fiala B, Blüthgen N. Specialization, constraints, and conflicting interests in mutualistic networks. Curr Biol. 2007;17:341-6. https://doi.org/10.1016/j.cub.2006.12.039. 
116. Benjamini Y, Hochberg Y. Controlling the false discovery rate: a practical and powerful approach to multiple testing. J R Stat Soc B. 1995;85:289-300. http://dx.doi.org/10.1111/j.25176161.1995.tb02031.x.

117. Chao Y, Liu W, Chen Y, Chen W, Zhao L, Ding Q, et al. Structure, variation, and co-occurrence of soil microbial communities in abandoned sites of a rare earth elements mine. Environ Sci Technol. 2016;50:11481-90. https://doi.org/10.1021/acs.est.6b02284.

118. Banerjee S, Baah-Acheamfour M, Carlyle CN, Bissett A, Richardson AE, Siddique T, et al. Determinants of bacterial communities in Canadian agroforestry systems. Environ Microbiol. 2016;18:1805-16. https://doi:10.1111/1462-2920.1298.

119. Shi S, Nuccio EE, Shi ZJ, He Z, Zhou J, Firestone MK. The interconnected rhizosphere: high network complexity dominates rhizosphere assemblages. Ecol Lett. 2016;19:926-36. https://doi.org/10.1111/ele.12630.

120. Bader GD, Hogue CWV. Analyzing yeast protein-protein interaction data obtained from different sources. Nat Biotechnol. 2002;20:991-7. http://dx.doi.org/10.1038/nbt1002-991.

121. Tipton L, Müller CL, Kurtz ZD, Huang L, Kleerup E, Morris A, et al. Fungi stabilize connectivity in the lung and skin microbial ecosystems. Microbiome. 2018;6:12. https://doi.org/10.1186/s40168-0170393-0.

\section{Figures}



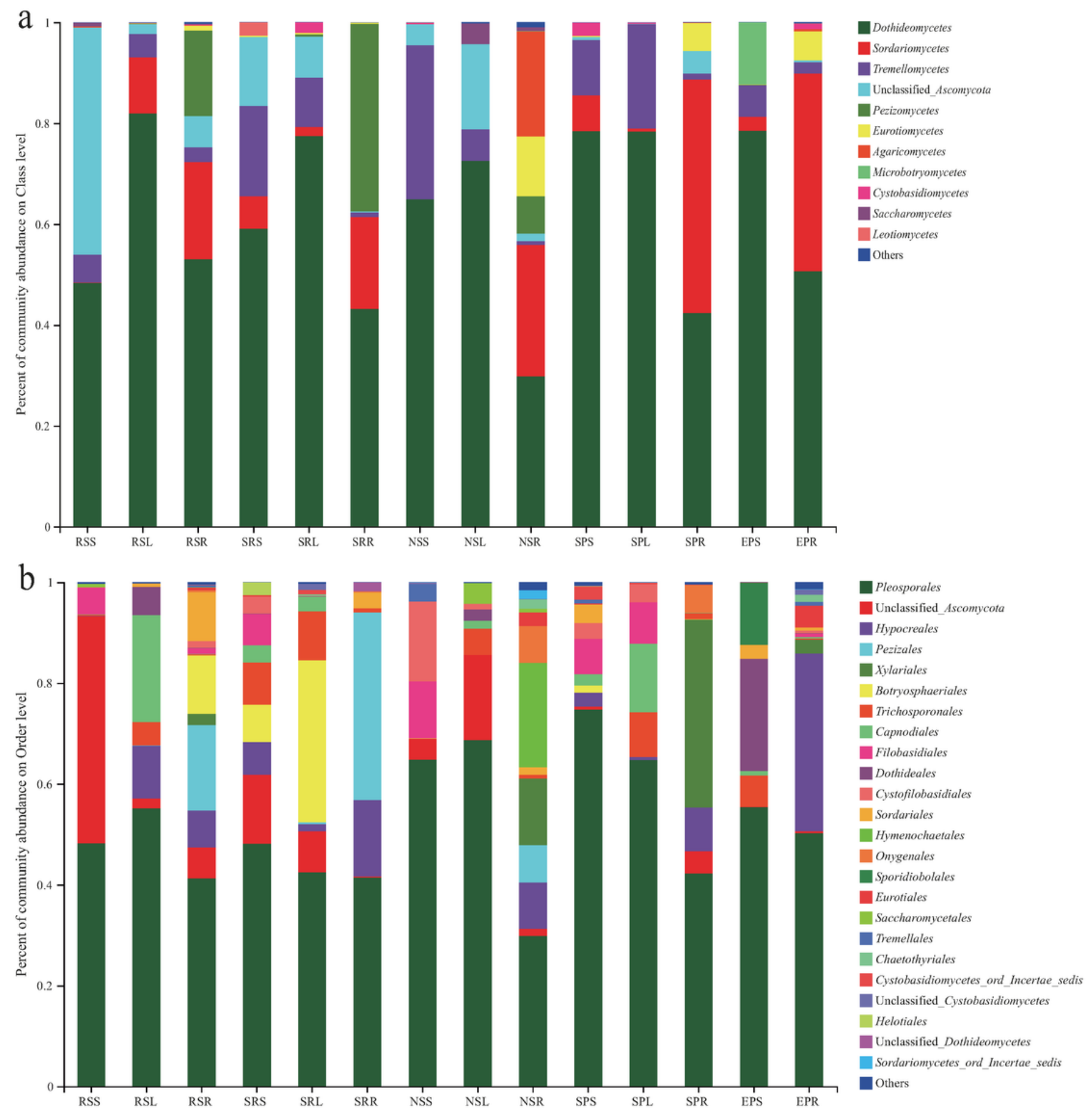

Figure 1

Relative abundance of endophytic fungi on class and order level in desert plants. The fungal class and order represents $<0.01 \%$ of the total reads of endophytic fungi were all assigned to "Others". RS, Reaumuria soongorica; SR, Sympegma regelii; NS, Nitraria sphaerocarpa; SP, Salsola passerina; EP, Ephedra przewalskii. S, stem; L, leaf; R, root. 

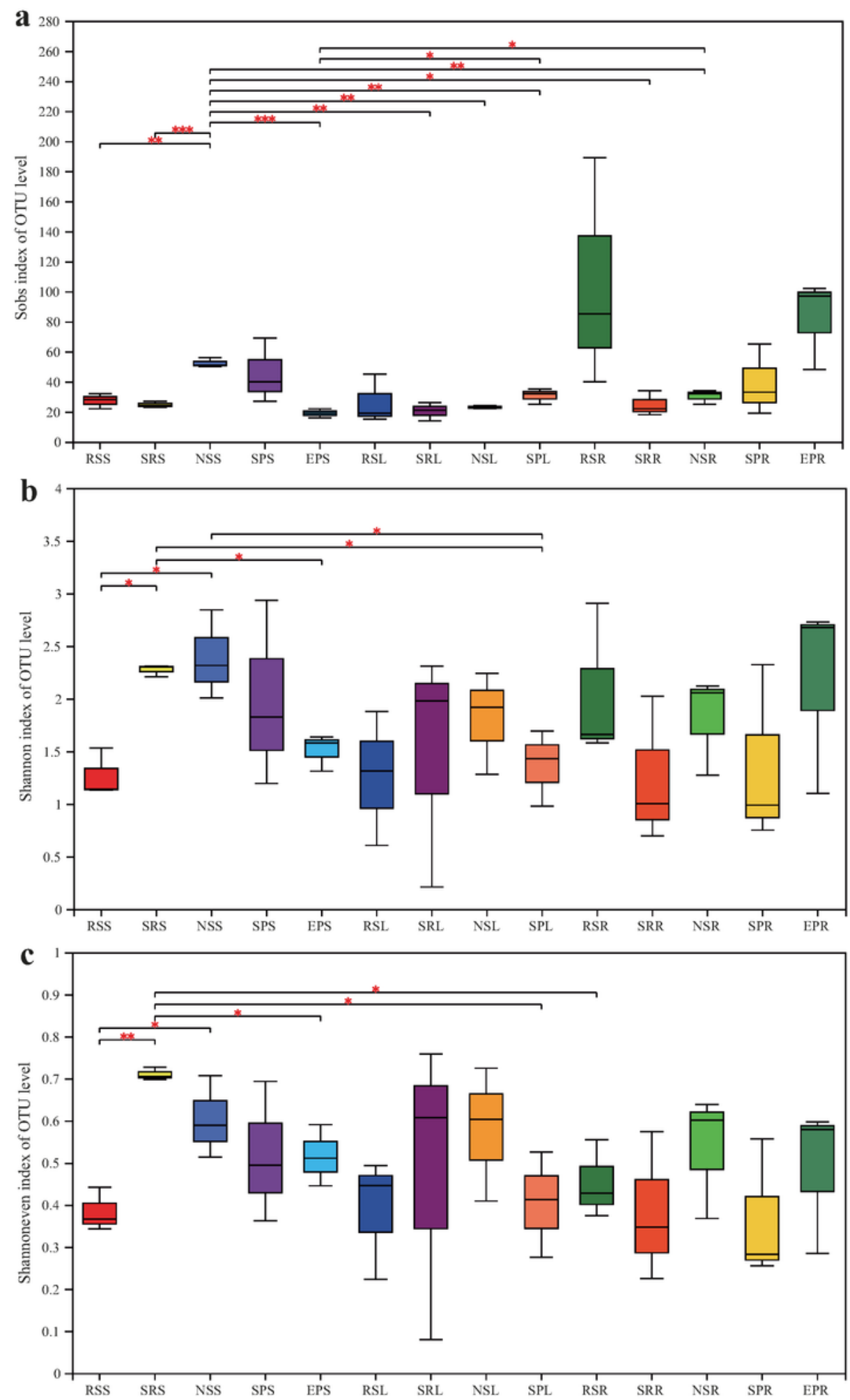

Figure 2

Operational taxonomic unit (OTU) richness and alpha diversity estimates of the fungal communities. The black line inside each box represents the median value. Kruskal-Wallis test revealed that plant species identity had a significant effect on the OTU richness of stem endophytic fungi $(X 2=10.939, P=0.027)$, but not on that of leaf $(X 2=3.308, P=0.347)$ and root compartment $(X 2=5.957, P=0.114)$. Alternatively, OUT richness was highly dependent on plant compartment $(\chi 2=6.612, P=0.037)$. Paired comparisons 
were performed by Welch's t tests for between samples. RS, Reaumuria soongorica; SR, Sympegma regelii; NS, Nitraria sphaerocarpa; SP, Salsola passerina; EP, Ephedra przewalskii. S, stem; L, leaf; R, root. *, $\mathrm{P} \leq 0.05 ; * *, \mathrm{P} \leq 0.01 ; * \star *, \mathrm{P} \leq 0.001$.
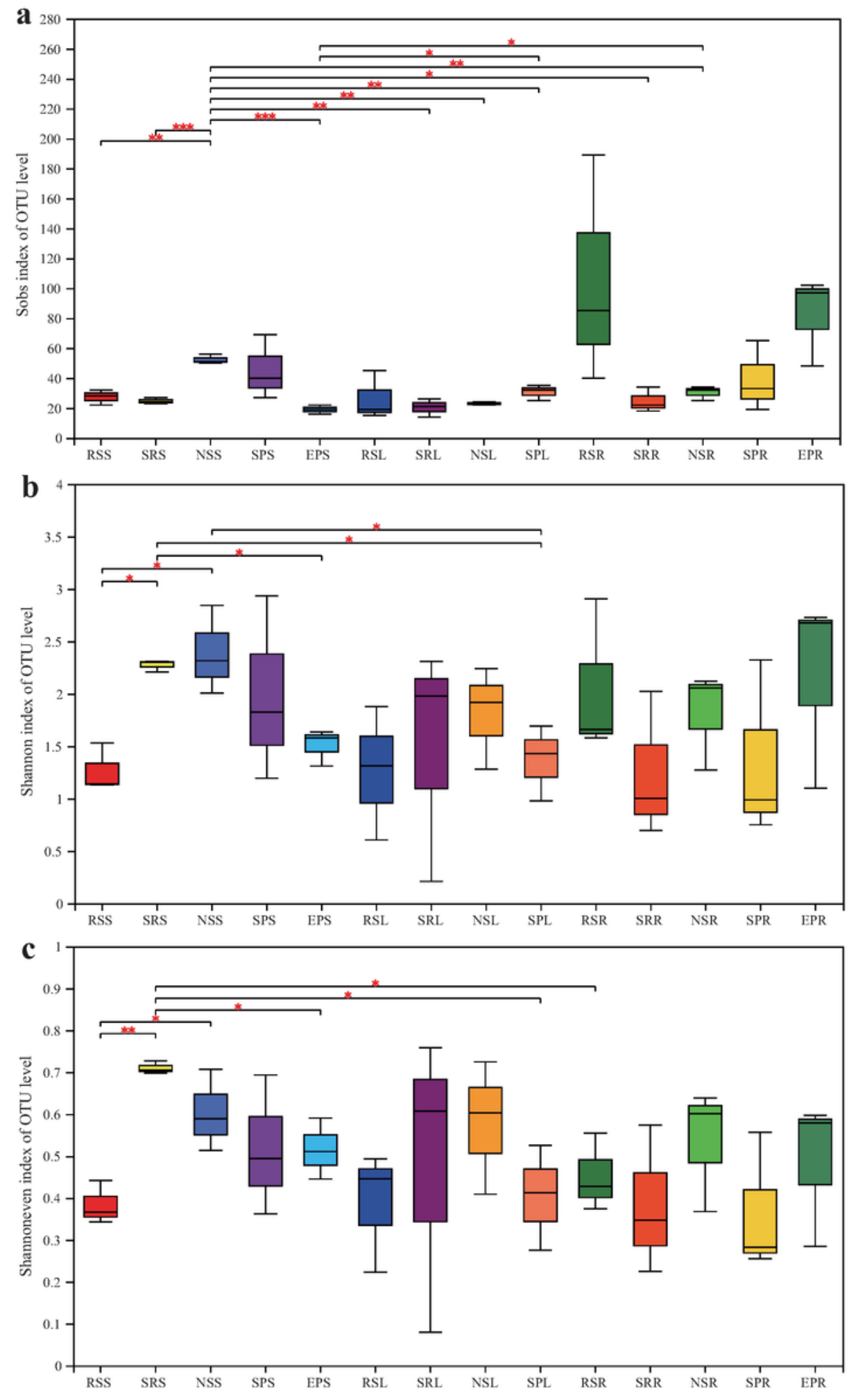

Figure 2

Operational taxonomic unit (OTU) richness and alpha diversity estimates of the fungal communities. The black line inside each box represents the median value. Kruskal-Wallis test revealed that plant species 
identity had a significant effect on the OTU richness of stem endophytic fungi $(X 2=10.939, P=0.027$ ), but not on that of leaf $(X 2=3.308, P=0.347)$ and root compartment $(X 2=5.957, P=0.114)$. Alternatively, OUT richness was highly dependent on plant compartment $(X 2=6.612, P=0.037)$. Paired comparisons were performed by Welch's t tests for between samples. RS, Reaumuria soongorica; SR, Sympegma regelii; NS, Nitraria sphaerocarpa; SP, Salsola passerina; EP, Ephedra przewalskii. S, stem; L, leaf; R, root. *, $P \leq 0.05 ; * \star, P \leq 0.01 ; * \star \star, P \leq 0.001$.
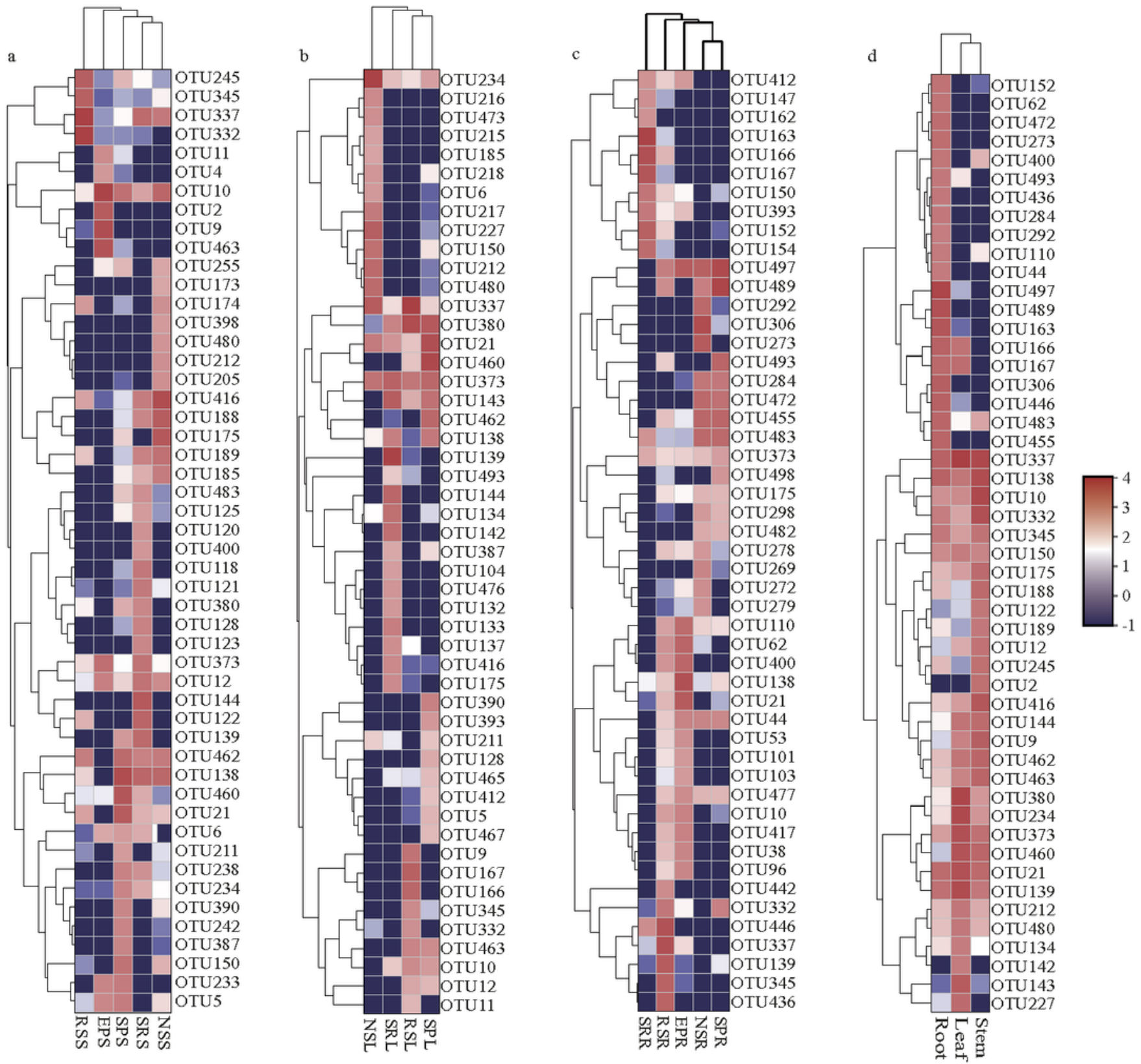

Figure 3 
Heatmap depicting the occurrences of relatively abundant fungal operational taxonomic units (OTUs, > 1000 reads). a, Stem endophytic fungi; b Leaf endophytic fungi; c Root endophytic fungi; $d$ Endophytic fungi in different tissue niches. The color of each heat map cell indicates the relative abundance of the corresponding fungal OTUs. Cluster analysis was performed based on Bray-Curtis similarities. RS, Reaumuria soongorica; SR, Sympegma regelii; NS, Nitraria sphaerocarpa; SP, Salsola passerina; EP, Ephedra przewalskii. S, stem; L, leaf; R, root.
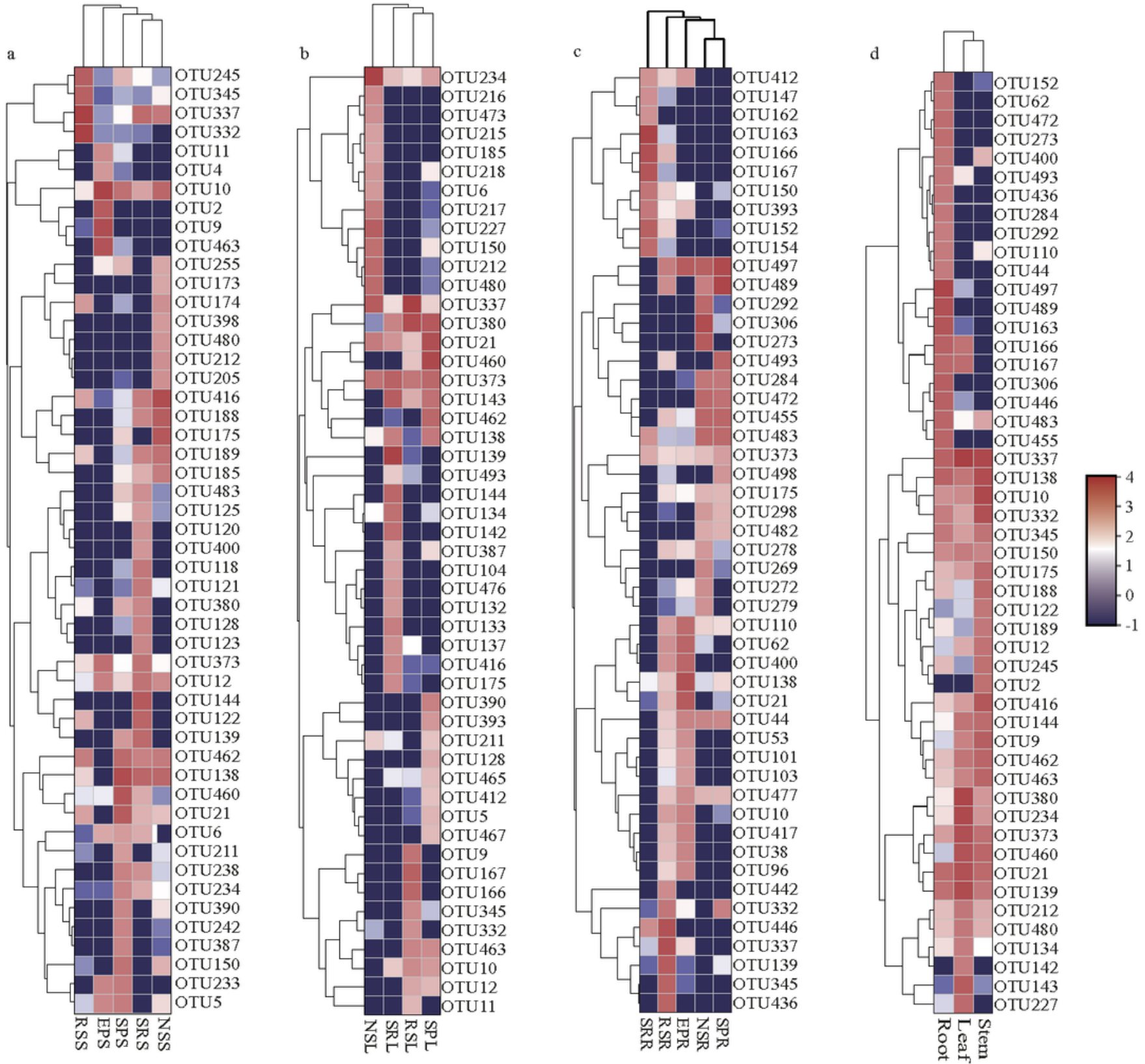

Figure 3 
Heatmap depicting the occurrences of relatively abundant fungal operational taxonomic units (OTUs, > 1000 reads). a, Stem endophytic fungi; b Leaf endophytic fungi; c Root endophytic fungi; d Endophytic fungi in different tissue niches. The color of each heat map cell indicates the relative abundance of the corresponding fungal OTUs. Cluster analysis was performed based on Bray-Curtis similarities. RS, Reaumuria soongorica; SR, Sympegma regelii; NS, Nitraria sphaerocarpa; SP, Salsola passerina; EP, Ephedra przewalskii. S, stem; L, leaf; R, root.
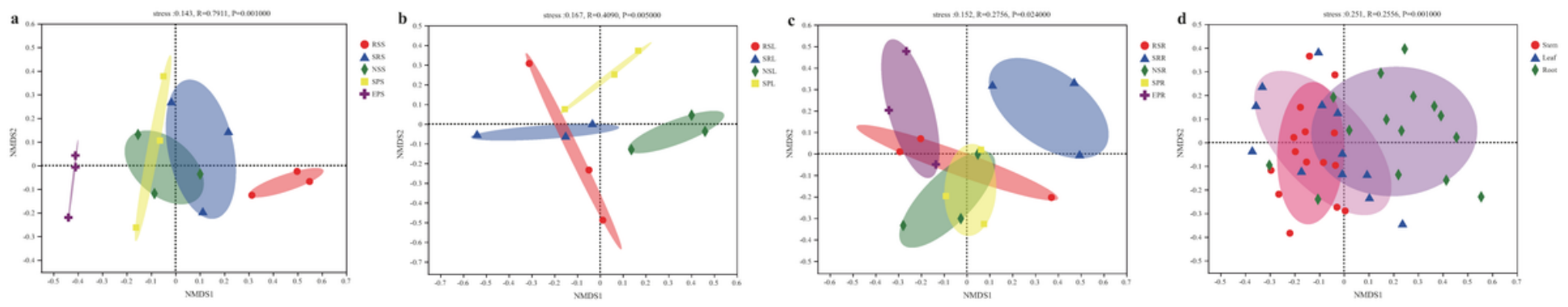

\section{Figure 4}

Nonmetric multidimensional scaling (NMDS) ordination of the fungal community composition. a, Stem endophytic fungi; $b$ Leaf endophytic fungi; c Root endophytic fungi; $d$ Endophytic fungi in different tissue niches. The dissimilarities of endophytic fungi were based on the Bray-Curtis method and the nonparametric ANOSIM test (an analogue of univariate ANOVA) was used to examine the significant difference based on 999 permutations. Ellipses in the plots represent the grouping interval of endophytic fungi in different plant species ( $a, b, c)$ and tissue niches (d). RS, Reaumuria soongorica; SR, Sympegma regelii; NS, Nitraria sphaerocarpa; SP, Salsola passerina; EP, Ephedra przewalskii. S, stem; L, leaf; R, root.
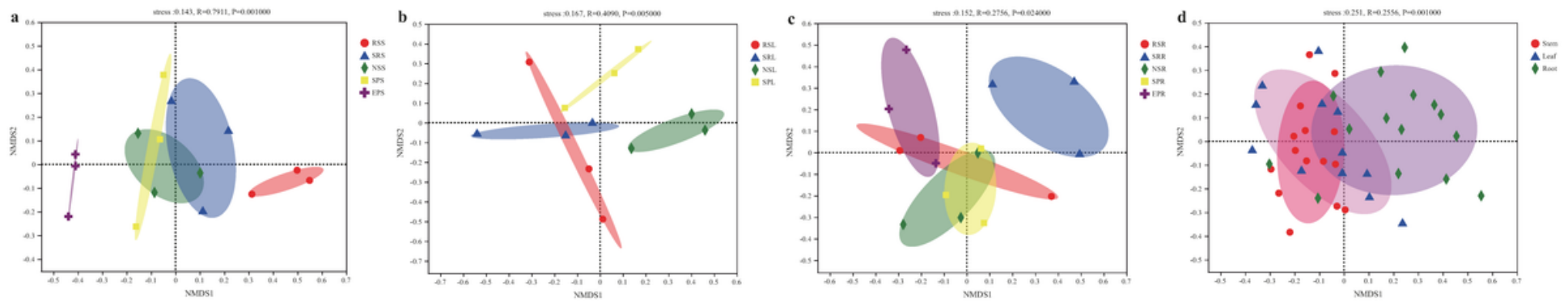

\section{Figure 4}

Nonmetric multidimensional scaling (NMDS) ordination of the fungal community composition. a, Stem endophytic fungi; $b$ Leaf endophytic fungi; c Root endophytic fungi; $d$ Endophytic fungi in different tissue niches. The dissimilarities of endophytic fungi were based on the Bray-Curtis method and the nonparametric ANOSIM test (an analogue of univariate ANOVA) was used to examine the significant difference based on 999 permutations. Ellipses in the plots represent the grouping interval of endophytic fungi in different plant species ( $a, b, c)$ and tissue niches (d). RS, Reaumuria soongorica; SR, Sympegma regelii; NS, Nitraria sphaerocarpa; SP, Salsola passerina; EP, Ephedra przewalskii. S, stem; L, leaf; R, root. 

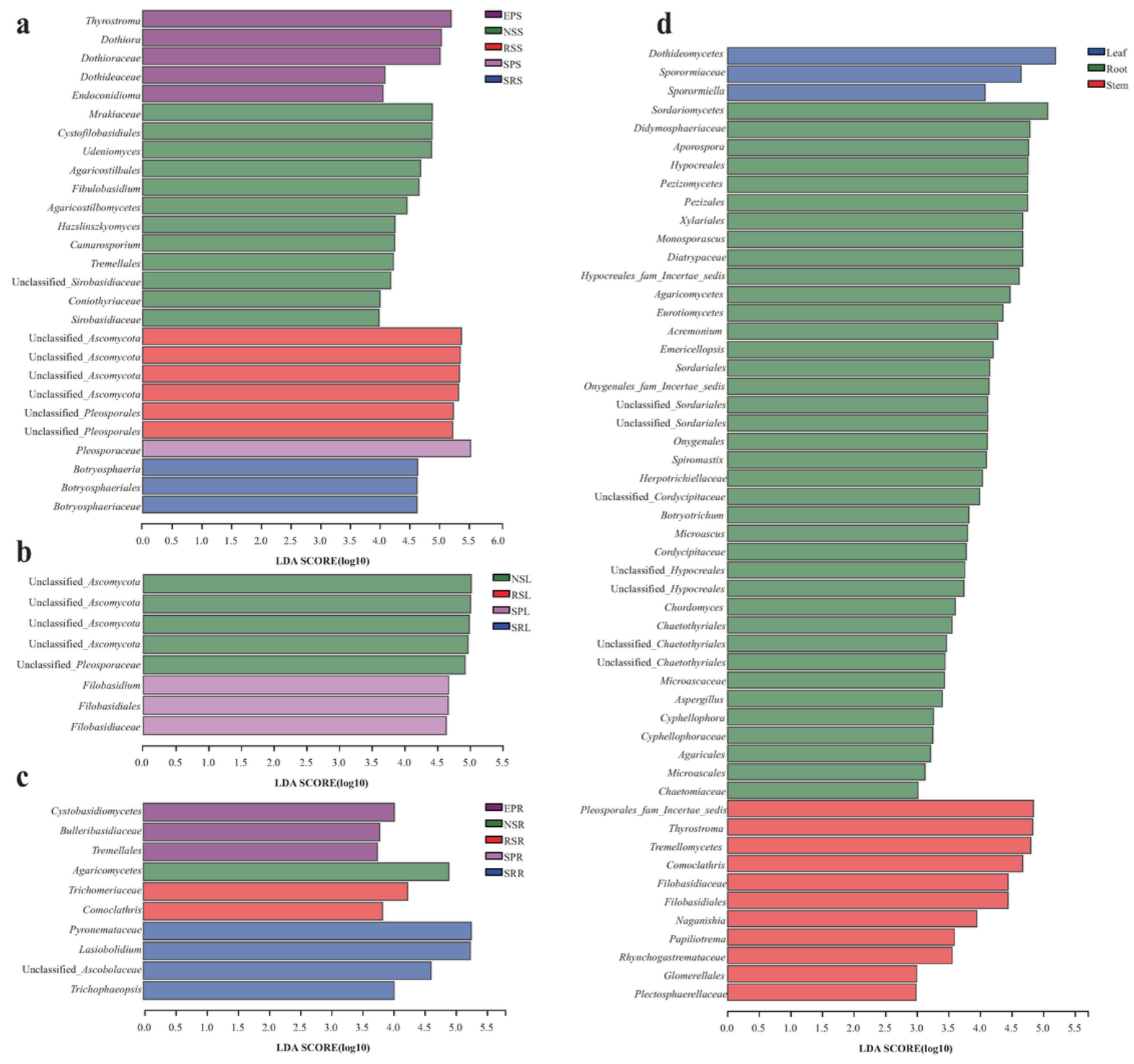

Figure 5

Indicator fungus with LDA scores of 4 or greater in desert plants and tissue niches. LDA Effect Size (LEfSe) algorithm was used on OTUs level to determine taxa that differentially represented between different host species and tissues. RS, Reaumuria soongorica; SR, Sympegma regelii; NS, Nitraria sphaerocarpa; SP, Salsola passerina; EP, Ephedra przewalskii. S, stem; L, leaf; R, root. 

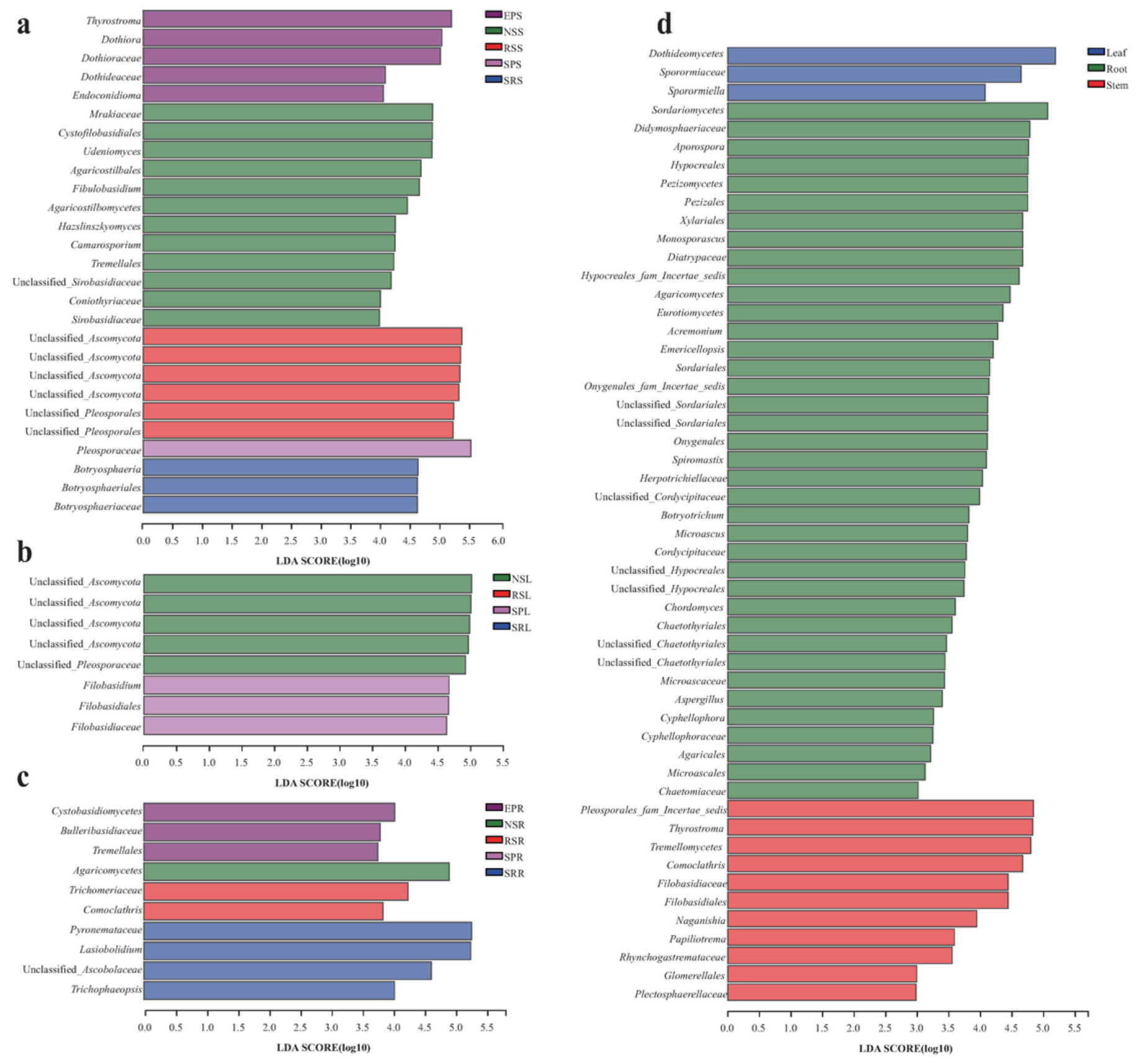

Figure 5

Indicator fungus with LDA scores of 4 or greater in desert plants and tissue niches. LDA Effect Size (LEfSe) algorithm was used on OTUs level to determine taxa that differentially represented between different host species and tissues. RS, Reaumuria soongorica; SR, Sympegma regelii; NS, Nitraria sphaerocarpa; SP, Salsola passerina; EP, Ephedra przewalskii. S, stem; L, leaf; R, root. 


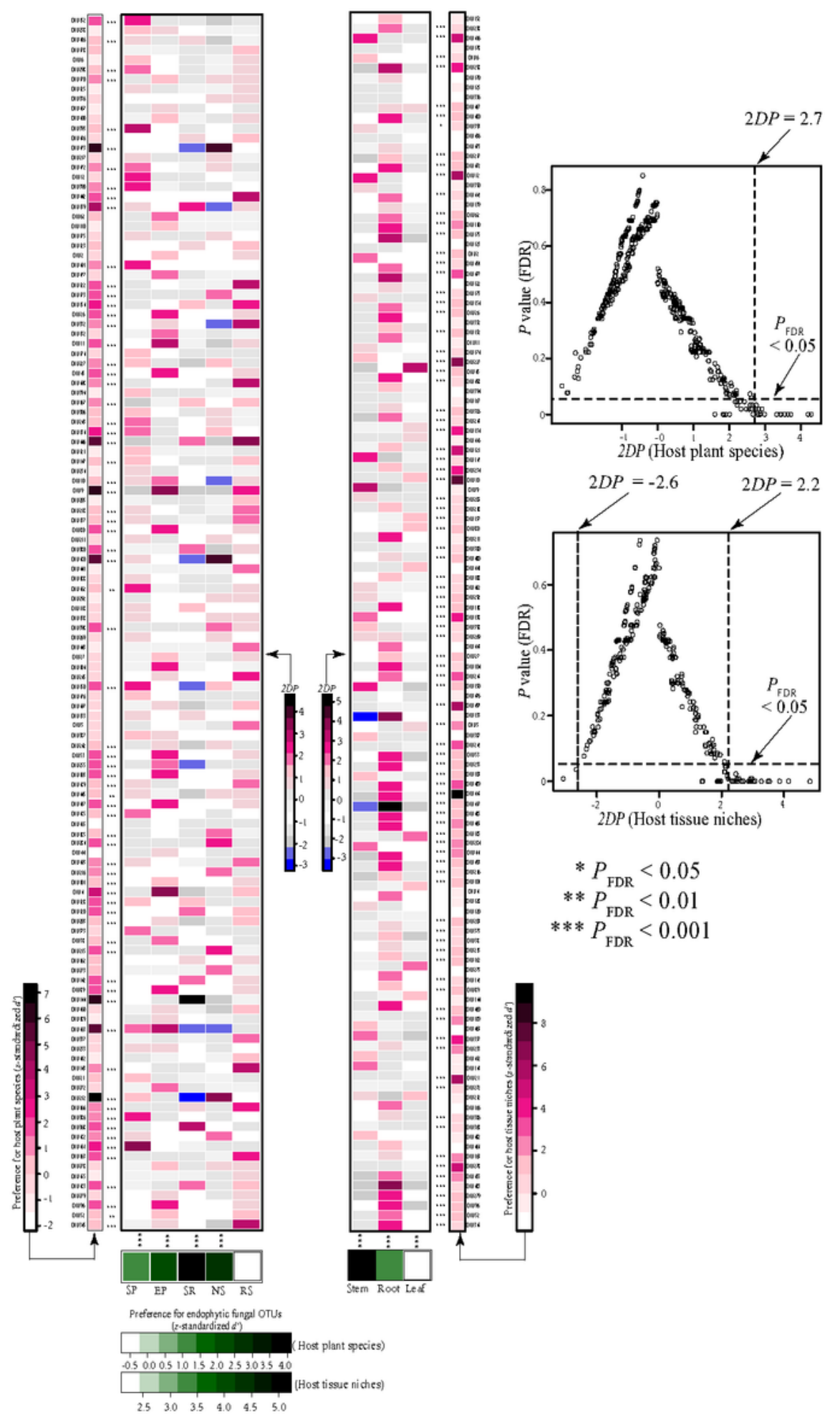

\section{Figure 6}

Analysis of host-tissue/fungus preferences. The standardized d' estimate of preferences for fungal operational taxonomic units (OTUs) are shown for each hosts and tissue niches (column). Likewise, the standardized d' estimate of preferences for plant species and tissue niches are indicated for each of the observed fungal OTUs (row). Each cell in the matrix indicates a two-dimensional preference (2DP) estimate, which evaluates to what extent each pair of each plant/tissue-fungus association was 
observed (counts) more or less frequently than would be expected by chance. The $\mathrm{P}$ values were adjusted based on the false discovery rate (FDR). RS, Reaumuria soongorica; SR, Sympegma regelii; NS, Nitraria sphaerocarpa; SP, Salsola passerina; EP, Ephedra przewalskii.

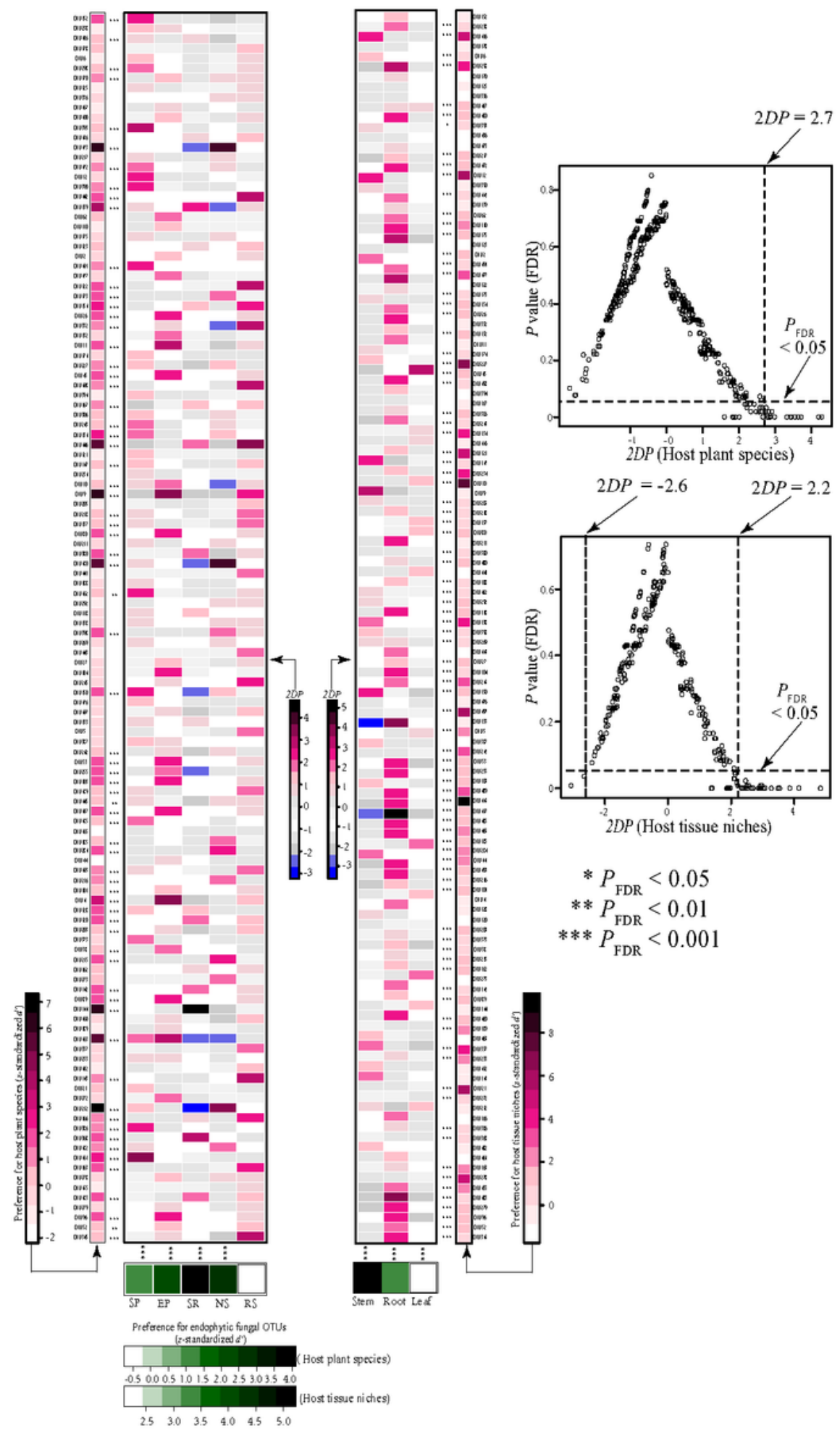

Figure 6

Analysis of host-tissue/fungus preferences. The standardized d' estimate of preferences for fungal operational taxonomic units (OTUs) are shown for each hosts and tissue niches (column). Likewise, the 
standardized d' estimate of preferences for plant species and tissue niches are indicated for each of the observed fungal OTUs (row). Each cell in the matrix indicates a two-dimensional preference (2DP) estimate, which evaluates to what extent each pair of each plant/tissue-fungus association was observed (counts) more or less frequently than would be expected by chance. The $P$ values were adjusted based on the false discovery rate (FDR). RS, Reaumuria soongorica; SR, Sympegma regelii; NS, Nitraria sphaerocarpa; SP, Salsola passerina; EP, Ephedra przewalskii.
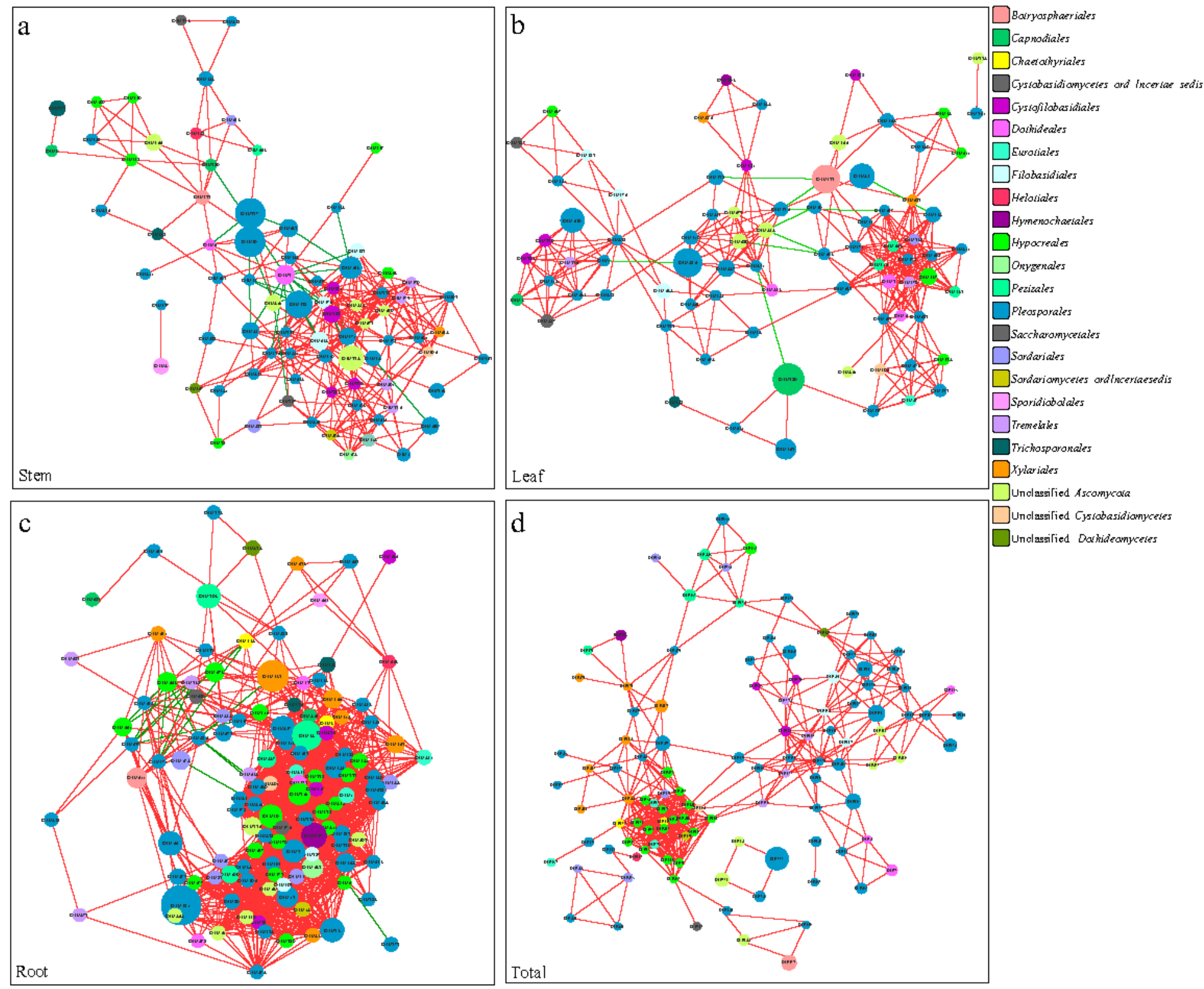
$\square$ Unclassilied Ascomycara
$\square$ Unclassilied Cysiabasidianyceles

\section{Figure 7}

Co-occurrence networks of microbial taxa in the fungal communities. Nodes represent fungal OTUs, whereas edges represent significant interactive correlations between pairs of OTUs. Node color represents the order of fungal OTUs and the size of nodes corresponds to the relative abundances of specific fungus. Red edges indicate positive relationships, and green edges indicate negative relationships. The thickness of each edge is proportional to the $P$ values. 


\section{Supplementary Files}

This is a list of supplementary files associated with this preprint. Click to download.

- renamed1bba0.xls

- Fig.S1.pdf

- Fig.S1.pdf

- Fig.S2.pdf

- Fig.S2.pdf

- Fig.S3.pdf

- Fig.S3.pdf

- Fig.S4.pdf

- Fig.S4.pdf

- Additionalfile3.docx

- Additionalfile3.docx 